\title{
Structural Screening and Design of Dendritic Micro-Mesoporous Composites for Efficient Hydrodesulfurization of Dibenzothiophene and 4,6-Dimethyldibenzothiophene
}

\author{
Xilong Wang ${ }^{\dagger}, \ddagger$, Chengkun Xiao ${ }^{\dagger}$, Jinlin Mei ${ }^{\dagger}$, Mohnnad H. Alabsi ${ }^{\ddagger}$, Yu Shi ${ }^{\dagger}$, Zhen \\ Zhao $^{\dagger}$, Aijun Duan ${ }^{\dagger}, *$, Kuo-Wei Huang $\stackrel{\ddagger}{+} *$, Chunming $\mathrm{Xu}^{\dagger}, *$ \\ $\dagger$ State Key Laboratory of Heavy Oil Processing, China University of Petroleum \\ (Beijing), Beijing 102249, P.R. China, \\ $\ddagger$ KAUST Catalysis Center and Division of Physical Sciences and Engineering, King \\ Abdullah University of Science and Technology, Thuwal 23955-6900, Saudi Arabia
}

Corresponding Author: *E-mail: duanaijun@cup.edu.cn;

*E-mail: hkw@kaust.edu.sa;

*E-mail:xcm@cup.edu.cn. 


\begin{abstract}
Novel dendritic micro-mesoporous TS-1/dendritic mesoporous silica nanoparticles (DMSNs) composites (TD) were assembled by TS-1 nanocrystals with ultrasmall particle size and strong acidity. TS-1 seeds and DMSNs were composited via the Ti-O-Si chemical bond, which stimulate on the generation of Brønsted (B) and Lewis (L) acid. The spillover d-electrons produced by The Ti element of TS-1 seeds produced a spillover of d-electrons, which could interact with the surface of $\mathrm{MoS}_{2}$ phases, thereby reducing Mo-S interactions and creat sulfur vacancies that are favorable for dibenzothiophene (DBT) and 4,6-dimethyldibenzothiophene (4,6-DMDBT) hydrodesulfurization (HDS) reactions. The increased B\&L acid amount of NiMo/TD-2.0 with Cetyltrimethylammonium bromide/Sodium salicylate molar ratio of 2.0 played a important role in facilitating the hydrogenation (HYD) route of DBT HDS and the isomerization (ISO) route of 4,6-DMDBT HDS, which is more favorable to the reduction of steric hindrance of DBT and 4,6-DMDBT reactants in the HDS reaction process. The NiMo/TD-2.0 catalyst exhibited the highest turn-over frequency (TOF) value and HDS reaction rate constant $\left(k_{H D S}\right)$ of DBT and 4,6-DMDBT due to its ultrasmall particle size, uniform spherical dendritic morphology, strong B\&L acidities and good stacking degree.
\end{abstract}

\title{
KEYWORDS
}

Dendritic composite; TS-1 seed; Ultrasmall particle size; Dibenzothiophenes; Hydrodesulfurization

\section{INTRODUCTION}

Strict environmental laws and regulations have been implemented in the world to reduce the emission of toxic gases from transportation fuels. ${ }^{1-7}$ Sulfur-containing species in transportation fuels are intrinsic to produce $\mathrm{SO}_{2}$ after combustion in the engine. ${ }^{8,9}$ In order to reduce the environmental impact, HDS of sulfur-containing species in transportation fuels is considered one of the main approaches. ${ }^{10,11}$ As the 
typical stubborn sulfocompounds, DBT and 4,6-DMDBT are usually taken as the feedstock in the study of ultra-deep HDS of transportation fuels. ${ }^{12-17}$ Traditional HDS catalysts of alumina supported tungsten or molybdenum promoted by nickel or cobalt have been identified unable to meet the requirements of the latest ultra-deep HDS due to their high metal-support interaction (MSI) and low hydrogenation activity. ${ }^{18-22}$

In order to ultra-deep removal of sulfur in transportation fuels, design of new HDS catalytic materials and catalysts for realizing high efficiency of hydrogenolysis of sulfides is needed. ${ }^{23-27}$ Mesoporous materials are widely used in the catalysis processes because of their excellent physicochemical properties of surface area and pore structure. In particular, DMSNs have received considerable attraction owing to their open three-dimensional dendritic pores and center-radial pore structures, which can provide highly accessible surfaces and short diffusion paths during the catalytic reaction. ${ }^{28-32}$ However, pure DMSNs are unsuitable for applications in the HDS reactions due to its weak acidity and inferior hydrothermal stability. ${ }^{33,} 34$ These issues could be addressed by introducing microporous zeolites such as ZSM-5, Beta, Y and TS-1 into mesoporous materials due to their good acidities and superior hydrothermal stabilities. ${ }^{35-37}$ While among all the zeolites, TS-1 shows outstanding properties such as small crystal size, low cost, facile method and active Ti atom framework, which can reduce the cost of catalyst and improve the activity of catalyst simultaneously, ${ }^{38,}$ 39 the synthesis of dendritic micro-mesoporous TD composites assembled by TS-1 nanocrystals with superior structural properties, such as uniform morphology, large pore diameter and small particle size, still faces a considerable challenge. Moreover, it is very difficult but necessary to regulate both the structural and acidic properties at the same time.

Herein, a series of dendritic TD composites with superior texture properties and acidities were successfully designed and screened. Various characterization methods were carried out on TD composites and the relevant NiMo/TD catalysts were examined to investigate the impact of structural and acidic properties on DBT and 4,6-DMDBT HDS reactions. The novel NiMo/TD catalyst with relatively small particle size $(\sim 90 \mathrm{~nm})$, uniform morphology and high acidity showed the highest TOF 
value and $k_{H D S}$ for DBT and 4,6-DMDBT. The relationship between the structural and acidic properties and the HDS performance and selectivity was presented.

\section{EXPERIMENTAL}

\subsection{Synthesis of supports}

\subsubsection{Synthesis of TS-1 nanocrystal}

The synthesis procedure of TS- 1 nanocrystal with the $\mathrm{SiO}_{2} / \mathrm{TiO}_{2}$ molar ratios of 25 is as follows. $40 \mathrm{~g}$ of tetraethyl orthosilicate (TEOS), $2.64 \mathrm{~g}$ tetrabutyl titanate, and $46.72 \mathrm{~g}$ TPAOH (25wt. \%) were added to $11.68 \mathrm{~g}$ of deionized water. The solution was agitated to dissolve for 1 hour in an ice water bath, then switched to a water bath at $70{ }^{\circ} \mathrm{C}$ for 3 hours. $48 \mathrm{~g}$ of isopropanol was added to the mix and agitated for 1 hour. The resulting mixture was moved to a $200 \mathrm{ml}$ autoclave at $170{ }^{\circ} \mathrm{C}$ for four days. Finally, TS-1 nanocrystal was obtained by centrifugation, washing, and drying.

\subsubsection{Synthesis of TD supports.}

Firstly, $0.82 \mathrm{~g}$ triethanolamine (TEA) was added in $300 \mathrm{ml}$ deionized water and stirred at $80{ }^{\circ} \mathrm{C}$ for 30 minutes. Secondly, a certain amount $(1.255 / 2.51 / 4.56 / 9.12 / 13.68 \mathrm{~g})$ of cetyltrimethylammonium bromide (CTAB) and $2.02 \mathrm{~g}$ sodium salicylate $(\mathrm{NaSal})$ were added and kept stirring for 1 hour. Thirdly, $48.0 \mathrm{~g}$ TEOS $\left(28.4 \mathrm{w} \% \mathrm{SiO}_{2}\right)$ was added dropwise and agitated for 30 minutes, then $1.86 \mathrm{~g}$ of the as-synthesized TS-1 nanocrystal was added and kept stirring for 1.5 hours. Fourthly, the resulting mixture was transferred to a $500 \mathrm{ml}$ autoclave at $100{ }^{\circ} \mathrm{C}$ for $4 \mathrm{~h}$. Finally, TD series composites $\left(\mathrm{SiO}_{2} / \mathrm{TiO}_{2}\right.$ molar ratios of 200) were prepared by adjusting the $\mathrm{CTAB} / \mathrm{NaSal}$ molar ratios $(0.25 / 0.5 / 1.0 / 2.0 / 3.0)$ and noted as TD-x, which $\mathrm{x}$ represents the $\mathrm{CTAB} / \mathrm{NaSal}$ molar ratios. Pure DMSN material was taken as the reference support, which was prepared under the similar conditions to TD material and only without addition of TS-1 nanocrystals in the third step.

\subsection{Preparation of the corresponding catalysts.}

NiMo catalysts with $15.0 \mathrm{wt} \% \mathrm{MoO}_{3}$ and $3.5 \mathrm{wt} \% \mathrm{NiO}$ were manufactured through stepwise incipient wetness impregnation of the series supports (TD-x, pure DMSNs and commercial $\left.\mathrm{Al}_{2} \mathrm{O}_{3}\right)$ using ammonium molybdate $\left(\left(\mathrm{NH}_{4}\right)_{6} \mathrm{Mo}_{7} \mathrm{O}_{24} \cdot 4 \mathrm{H}_{2} \mathrm{O}\right)$ 
and nickel nitrate $\left(\mathrm{Ni}\left(\mathrm{NO}_{3}\right)_{2} \cdot 6 \mathrm{H}_{2} \mathrm{O}\right)$. The as-prepared catalysts were labeled as NiMo/TD-0.25, NiMo/TD-0.5, NiMo/TD-1.0, NiMo/TD-2.0, NiMo/TD-3.0, $\mathrm{NiMo} / \mathrm{DNSNs}$ and $\mathrm{NiMo} / \mathrm{Al}_{2} \mathrm{O}_{3}$.

\subsection{Characterization and catalytic evaluation}

The analytical methods of XRD, ${ }^{29}$ Si MAS NMR, SEM, $\mathrm{H}_{2}$-TPR, Py-FTIR, XPS, HRTEM and the catalytic performance evaluation methods were introduced in the supporting information. And the calculation methods of average stacking number (Nav), average staking length (Lav), dispersion degree $\left(f_{M o}\right)$ of $\mathrm{MoS}_{2}$ stacking, $k_{H D S}$ and TOF of HDS reaction were described in the previous papers. ${ }^{40-44}$

\section{RESULTS}

\subsection{Characterization of supports}

\subsubsection{XRD}

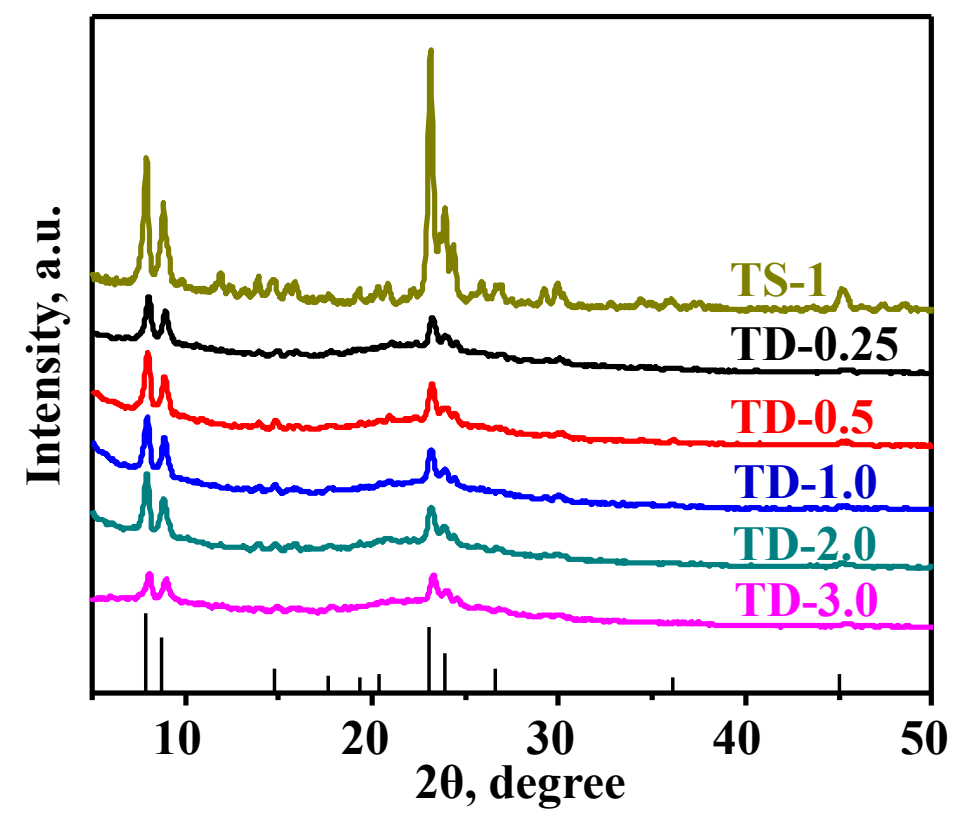

Figure 1. Wide angle XRD spectra of the various supports.

Figure 1 shows the XRD patterns of various TD materials and TS- 1 zeolite. All the TD composites display five characteristic peaks from $7.8-8.7^{\circ}$ to $22-25^{\circ}$, which are indicative of (011), (020), (051), (303), (313), and (532) reflections of TS-1 zeolite. ${ }^{45}$ Compared with the pure TS-1 zeolite, the peak intensities decrease with the addition of TS-1 seed, manifesting that some of the TS-1 seeds are embedded into the skeleton 
of DMSNs.

\subsubsection{SEM}

The SEM pictures of the various materials are presented in Figure 2. All the series TD composites show uniform wrinkled surfaces. The changes in particle sizes of TD composites can also be observed from these images. The particle sizes decrease from $350 \mathrm{~nm}$ to $75 \mathrm{~nm}$ with the increase of CTAB/NaSal molar ratios. Compared to DMSNs, TD-2.0 and TD-3.0 possess smaller particle size. Moreover, we can also find that the partial wrinkled surfaces of wrinkled TD- 0.25 particles are covered, which is not conducive to the diffusion of reactants and product molecules in the pore channel. The increase in $\mathrm{CTAB} / \mathrm{NaSal}$ molar ratios creates more micelles; thus more nuclei are generated, which cause in the formations of the dendritic TD composites with smaller sizes. ${ }^{31}$
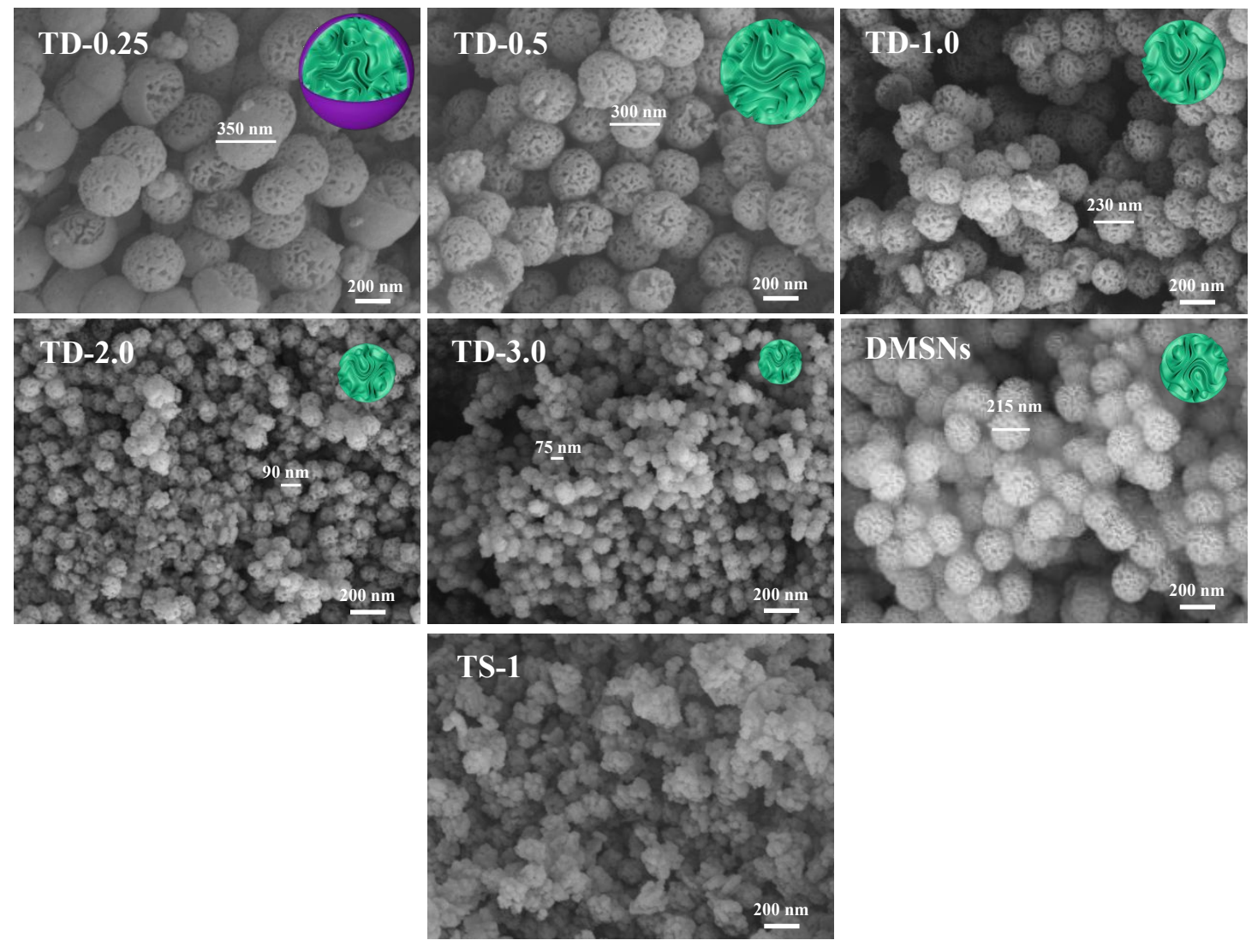

Figure 2. SEM images of the various materials.

\subsubsection{TEM and HAADF-STEM-EDS}



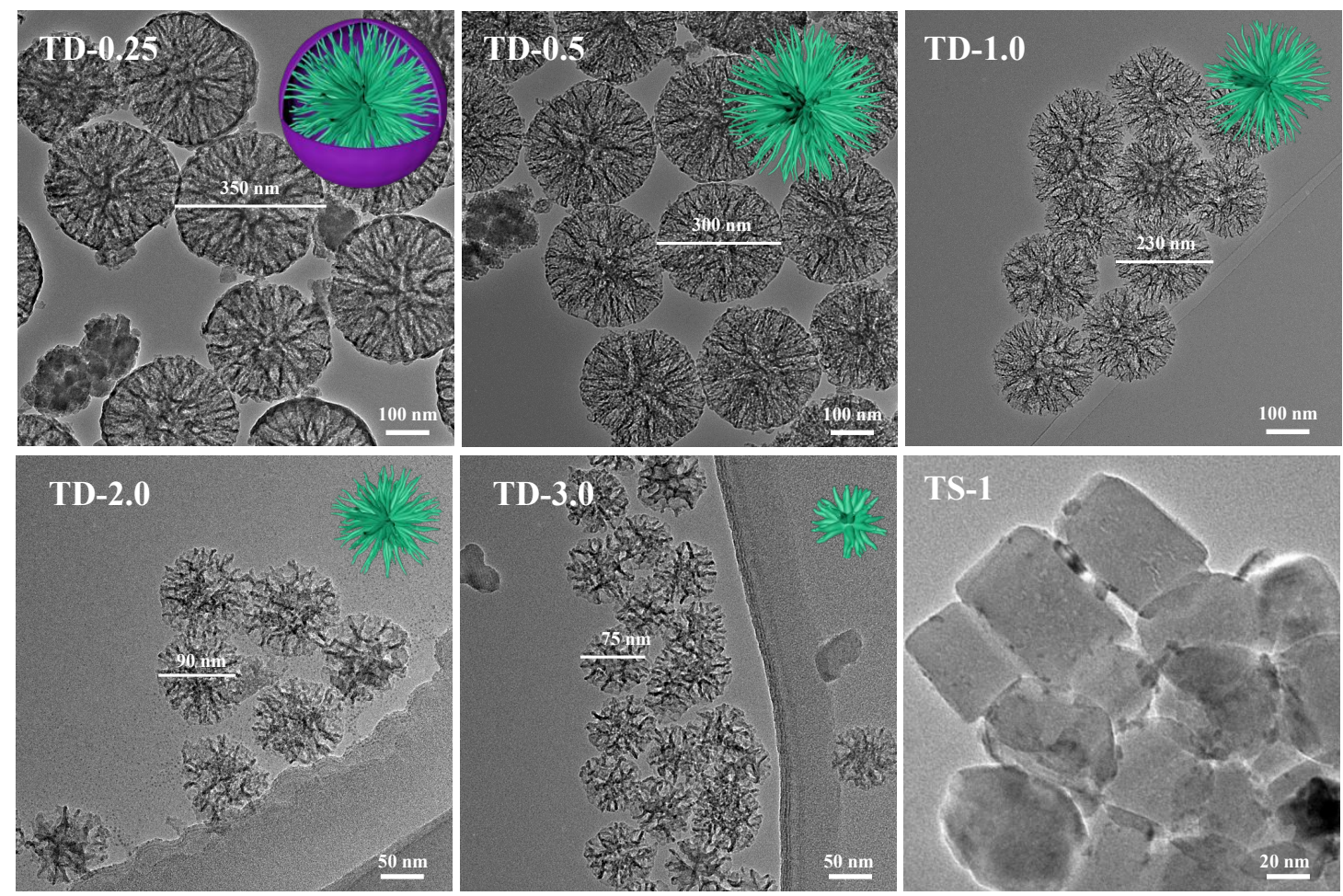

Figure 3. TEM images of various materials.

The TEM images of various TD materials with diverse particle sizes and TS-1 zeolite are exhibited in Figure 3. TS-1 zeolite has irregular square structure. All the series TD composites show uniform dendritic spherical particles and open center-radial pore structures. After adjusting the $\mathrm{CTAB} / \mathrm{NaSal}$ molar ratios, the particle sizes of dendritic TD supports directly decrease from $350 \mathrm{~nm}$ of TD-0.25 to $90 \mathrm{~nm}$ of TD-2.0 and continuing to shrink down to $75 \mathrm{~nm}$ of TD-3.0. When the $\mathrm{CTAB} / \mathrm{NaSal}$ molar ratio is small, the partial surfaces of dendritic TD-0.25 particles are covered, which may lead to the blockage of the pore channels. 

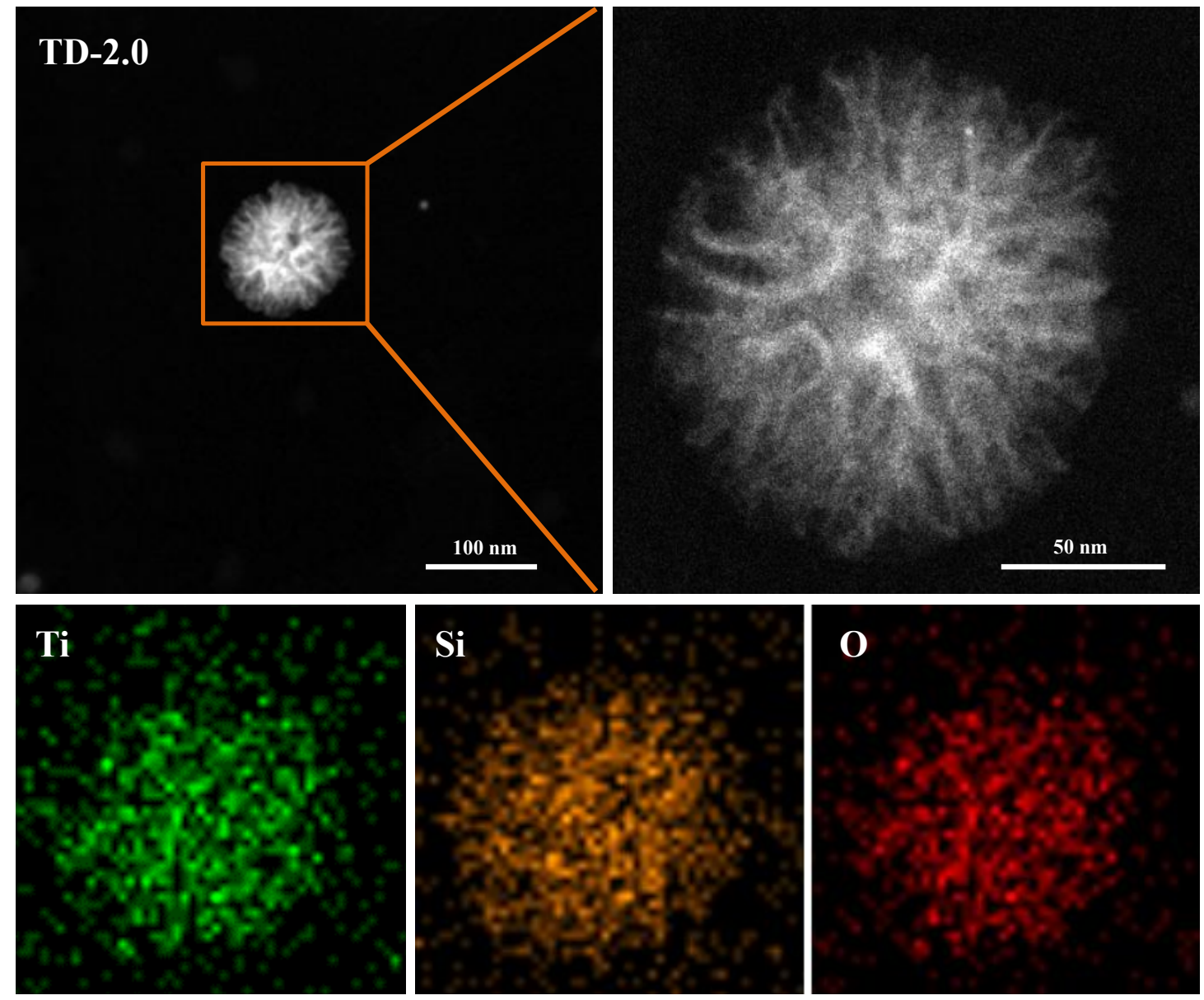

Figure 4. HAADF-STEM and EDS pictures (Ti, Si, O) of TD-2.0 support.

In order to study the distributions of $\mathrm{Ti}$ species in TD-2.0 support, HAADF-STEM and EDS mappings were carried out and the relevant imagines are presented in Figure 4. It can be found that the Ti elements are uniformly dispersed in the dendritic pore channels, manifesting that TS-1 seeds are successfully embedded into the DMSNs framework. More Ti elements in the framework of the series TD supports can produce more sulfur vacancies and provide electrons for the active metal, which are conducive to the improvement of the catalytic HDS activity. ${ }^{38}$

\subsubsection{FTIR}

The FTIR spectra of series supports are presented in Figure 5. Two characteristic peaks at the positions of 808 and $1068 \mathrm{~cm}^{-1}$ can be ascribed to the stretching vibrations of Si-O-Si bond, correspondingly. ${ }^{46}$ The characteristic peaks at $1640 \mathrm{~cm}^{-1}$ are ascribed to silanol (Si-OH). The characteristic peaks at $948 \mathrm{~cm}^{-1}$ are assigned to 
the Si-O-Ti bond. ${ }^{47}$ TD-2.0 possesses less silanol groups, fewer Si-O-Si and more Si-O-Ti bonds than other TD supports and TS-1 seed, suggesting that more TS- 1 seed are embedded into the DMSNs framework via Si-O-Ti bonds.

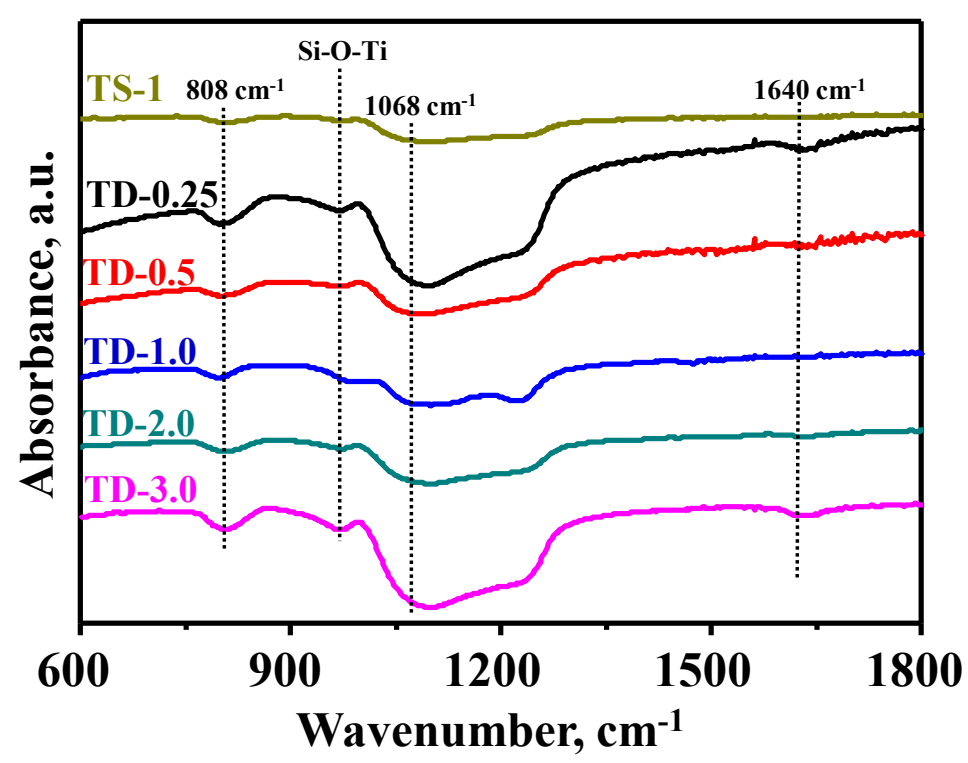

Figure 5. FTIR patterns of various supports.

\subsection{5 $\quad{ }^{29}$ Si NMR}

The ${ }^{29} \mathrm{Si}$ NMR patterns of series materials with various particle sizes are exhibited in Figure 6. The first peak at the position of $-102 \mathrm{~nm}(\mathrm{Q} 3)$ is ascribed to $\mathrm{Si}(\mathrm{OH})(-\mathrm{O}-)_{3}$ substance. The second peak at $-112 \mathrm{~nm}(\mathrm{Q} 4)$ is attributed to $\mathrm{Si}(-\mathrm{O}-)_{4}$ substance. ${ }^{48}$ The peak intensity of the series TD supports at the position of $-102 \mathrm{~nm}$ (Q3) is lower than that of DMSNs material. Combined with the results from FTIR, the H element of the $\mathrm{Si}(\mathrm{OH})(-\mathrm{O}-)_{3}$ of DMSNs may be replaced by Ti element of TS-1 during the introduction of TS-1 seed. Moreover, TD-2.0 support possesses more $\mathrm{Si}(-\mathrm{O}-)_{4}$ and less $\mathrm{Si}(\mathrm{OH})(-\mathrm{O}-)_{3}$ groups than those of TD-0.25, TD-3.0 and DMSNs, indicating more Si-O-Ti species are generated in the TD-2.0 framework. 


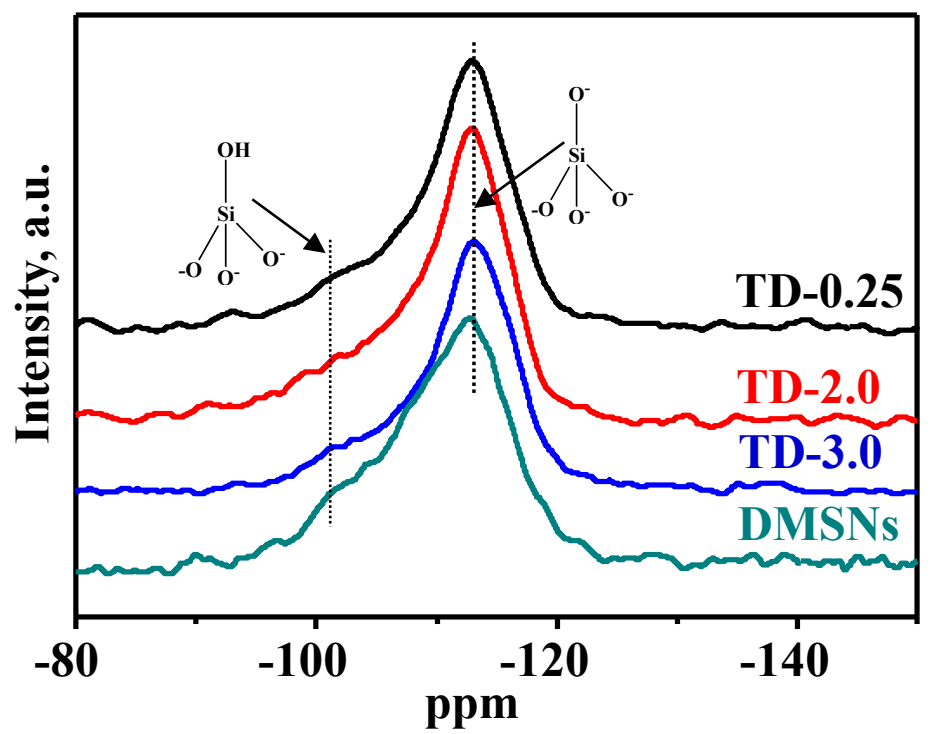

Figure 6. ${ }^{29} \mathrm{Si}$ NMR patterns of various materials.

\subsection{6 $\quad \mathrm{N}_{2}$ physisorption}
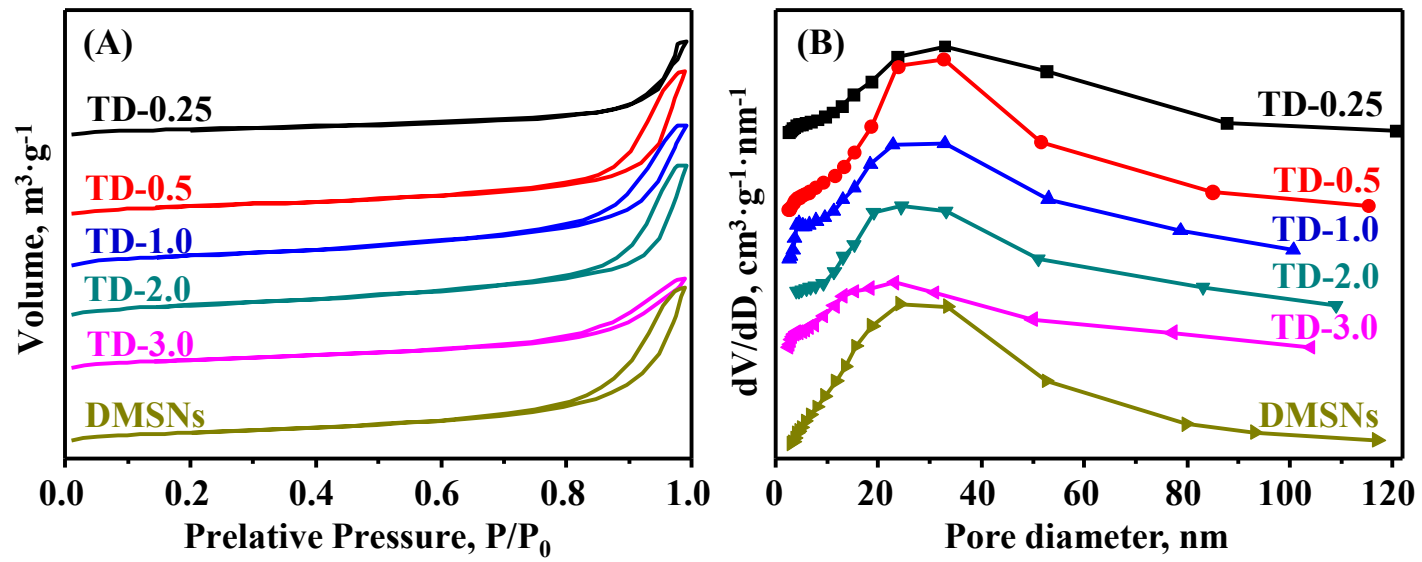

Figure 7. (A) $\mathrm{N}_{2}$ adsorption-desorption isotherms and (B) pore size distributions of TD materials and DMSNs.

Figure 7(A) and 7(B) display the $\mathrm{N}_{2}$ adsorption-desorption isotherms and pore size distributions of TD materials and DMSNs. $\mathrm{N}_{2}$ adsorption-desorption isotherms show that TD materials and DMSNs display type-IV curves with H2 hysteresis loops. The hysteresis loops of TD-0.25 and TD-3.0 are very narrow, which means the $\mathrm{N}_{2}$ adsorption amount is limited because of these two supports' relatively low surface areas. Figure 7(B) shows that the mesoporous structures are maintained after the addition of TS- 1 seeds. The pore size distributions of TD-2.0 are more concentrative 
than TD-0.25 and TD-3.0 supports.

Table 1. Textural parameter of various materials.

\begin{tabular}{cccccc}
\hline Samples & $\begin{array}{c}\mathrm{S}_{\mathrm{BET}} \\
\left(\mathrm{m}^{2} \mathrm{~g}^{-1}\right)\end{array}$ & $\begin{array}{c}\mathrm{S}_{\mathrm{EXT}}{ }^{\mathrm{a}} \\
\left(\mathrm{m}^{2} \mathrm{~g}^{-1}\right)\end{array}$ & $\begin{array}{c}\mathrm{S}_{\mathrm{MIC}}{ }^{\mathrm{b}} \\
\left(\mathrm{m}^{2} \mathrm{~g}^{-1}\right)\end{array}$ & $\begin{array}{c}\mathrm{V}_{\text {mes }} \\
\left(\mathrm{cm}^{3} \mathrm{~g}^{-1}\right)\end{array}$ & $\begin{array}{c}\mathrm{d}_{\mathrm{BJH}} \\
(\mathrm{nm})\end{array}$ \\
\hline TD-0.25 & 303 & 195 & 108 & 0.95 & 17.5 \\
TD-0.5 & 426 & 291 & 135 & 1.47 & 17.6 \\
TD-1.0 & 548 & 378 & 170 & 1.73 & 16.7 \\
TD-2.0 & 575 & 396 & 179 & 1.77 & 16.3 \\
TD-3.0 & 392 & 274 & 118 & 0.94 & 11.9 \\
DMSNs & 415 & 415 & 415 & 1.67 & 20.4 \\
TS-1 & 276 & 184 & 92 & 0.63 & - \\
\hline
\end{tabular}

${ }^{a}$ t-Plot extremal surface area.

${ }^{b}$ t-Plot microporous surface area.

The texture parameter of various TD materials and DMSNs are displayed in Table 1. As CTAB/NaSal molar ratios increase, the corresponding BET surface areas and pore volumes of various TD materials increase firstly from TD-0.25 (303 $\mathrm{m}^{2} \cdot \mathrm{g}^{-1}$, $\left.0.95 \mathrm{~cm}^{3} \cdot \mathrm{g}^{-1}\right)$ to TD-2.0 $\left(575 \mathrm{~m}^{2} \cdot \mathrm{g}^{-1}, 1.77 \mathrm{~cm}^{3} \cdot \mathrm{g}^{-1}\right)$, then decrease to TD-3.0 (392 $\left.\mathrm{m}^{2} \cdot \mathrm{g}^{-1}, 0.94 \mathrm{~cm}^{3} \cdot \mathrm{g}^{-1}\right)$. TD-2.0 presents the highest surface area and pore volume, and relatively concentrative pore size distribution among these TD supports, DMSNs and TS-1 zeolite, which are conducive to promoting the distribution of $\mathrm{MoS}_{2}$ species to improve the HDS performance.

\subsection{Characterization of the series NiMo Catalysts.}

\subsection{1 $\mathrm{H}_{2}-\mathrm{TPR}$}




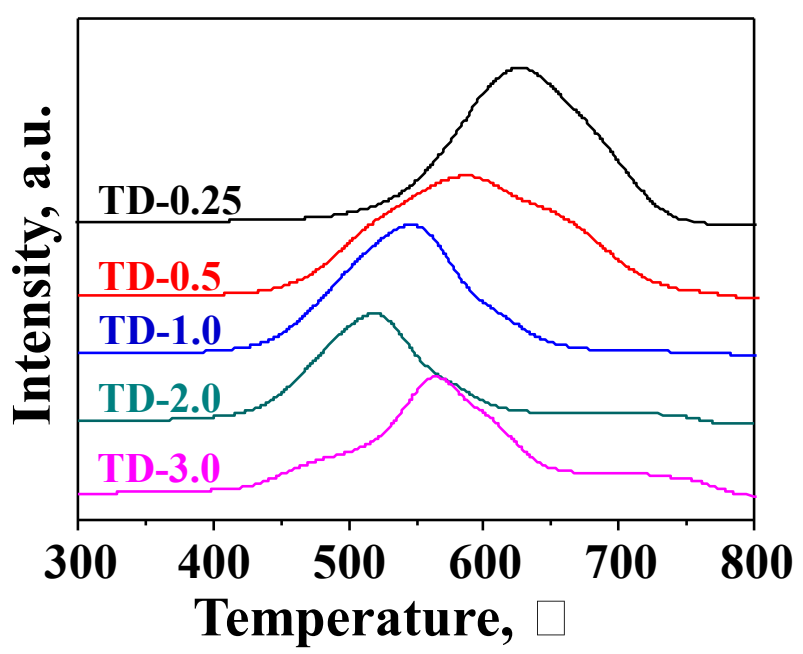

Figure 8. $\mathrm{H}_{2}$-TPR curves of various catalysts.

The MSI for different catalysts can be obtained from $\mathrm{H}_{2}$-TPR. The corresponding $\mathrm{H}_{2}$-TPR spectra for various catalysts are displayed in Figure 8. The $\mathrm{H}_{2}$-TPR patterns of series NiMo/TD catalysts display two peaks. The low reduction temperature peak is corresponding to the reduction of $\mathrm{Mo}^{6+}$ to $\mathrm{Mo}^{4+}$. The high reduction temperature peak is assigned to the reduction step of $\mathrm{Mo}^{4+}$ to $\mathrm{Mo}^{0} .{ }^{49}$ The reduction temperatures of the two peaks increase following the sequence of NiMo/TD-2.0 $<\mathrm{NiMo/TD-1.0<}$ $\mathrm{NiMo} / \mathrm{TD}-3.0<\mathrm{NiMo} / \mathrm{TD}-0.5<\mathrm{NiMo} / \mathrm{TD}-0.25$. NiMo/TD-2.0 catalyst shows lower $\mathrm{H}_{2}$ reduction temperature than other $\mathrm{NiMo} / \mathrm{TD}$ catalyst, suggesting that $\mathrm{NiMo} / \mathrm{TD}-2.0$ possesses more active sites that are easy to be reduced and presulfurized.

\subsubsection{Py-FTIR}
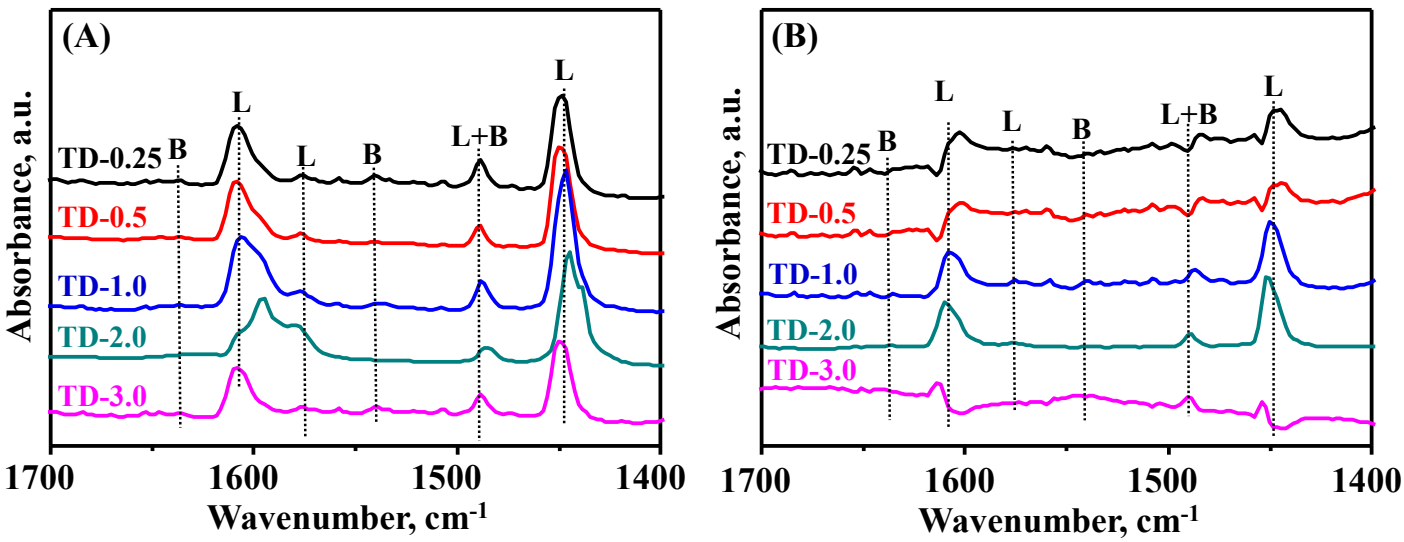

Figure 9. Py-FTIR patterns of various materials at (A) $200^{\circ} \mathrm{C}$ and (B) $350{ }^{\circ} \mathrm{C}$. 
Table 2. Acidy of the series NiMo catalysts.

\begin{tabular}{|c|c|c|c|c|c|c|c|c|}
\hline \multirow[t]{3}{*}{ Catalysts } & \multicolumn{8}{|c|}{ Amount of acid sites $\left(\mu \mathrm{mol} \mathrm{g} \mathrm{g}^{-1}\right)$} \\
\hline & \multicolumn{3}{|c|}{$200^{\circ} \mathrm{C}$} & & \multicolumn{3}{|c|}{$350^{\circ} \mathrm{C}$} & \\
\hline & $\mathrm{L}$ & $\mathrm{B}$ & $\mathrm{L}+\mathrm{B}$ & $\mathrm{B} / \mathrm{L}$ & $\mathrm{L}$ & B & $\mathrm{L}+\mathrm{B}$ & $\mathrm{B} / \mathrm{L}$ \\
\hline NiMo/TD-0.25 & 58.3 & 1.1 & 59.4 & 0.02 & 16.5 & 0 & 16.5 & 0 \\
\hline NiMo/TD-0.5 & 67.4 & 2.4 & 69.8 & 0.04 & 20.6 & 1.2 & 21.8 & 0.06 \\
\hline NiMo/TD-1.0 & 91.2 & 5.1 & 96.3 & 0.06 & 25.4 & 1.9 & 27.3 & 0.07 \\
\hline $\mathrm{NiMo} / \mathrm{TD}-2.0$ & 112.5 & 6.3 & 118.8 & 0.06 & 33.1 & 3.1 & 36.2 & 0.09 \\
\hline $\mathrm{NiMo} / \mathrm{TD}-3.0$ & 78.6 & 2.9 & 81.5 & 0.04 & 22.4 & 1.3 & 23.7 & 0.06 \\
\hline
\end{tabular}

Py-FTIR patterns were applied to study NiMo supported catalysts' acidic properties, which are presented in Figure 9. The patterns acquired through degassing at $200{ }^{\circ} \mathrm{C}$ and $350{ }^{\circ} \mathrm{C}$ are assigned to the total acids, and the medium and strong acids, correspondingly. ${ }^{50}$ The corresponding quantification results are listed in Table 2 . The total acid amounts, the medium and strong acid amounts increase following the sequence of NiMo/TD-0.25 $<$ NiMo/TD-0.5 $<$ NiMo/TD-3.0 $<$ NiMo/TD-1.0 < NiMo/TD-2.0. NiMo/TD-2.0 catalyst has the most B \& L acid, which facilitating to the HDS reaction along with the HYD path and the ISO path.

\subsubsection{Raman}

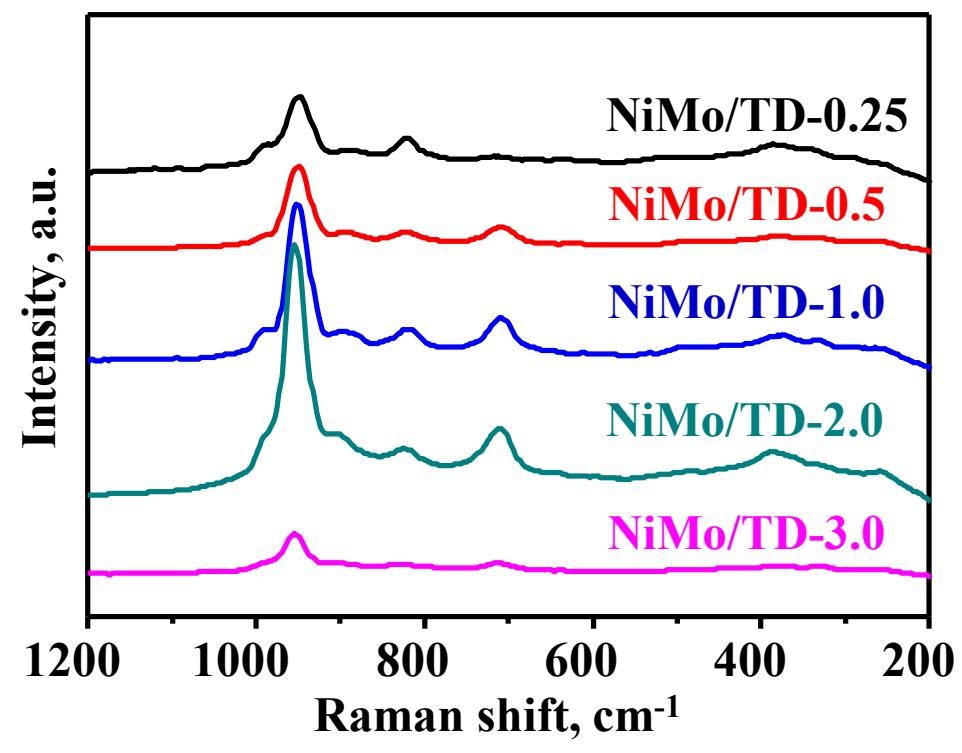

Figure 10. Raman patterns of various catalysts. 
Raman spectra of various NiMo supported catalysts are displayed in Figure 10. The characteristic peaks at $826 \mathrm{~cm}^{-1}$ are assigned to $\mathrm{NiMoO}_{4}$ species. ${ }^{51}$ The characteristic peaks at $955 \mathrm{~cm}^{-1}$ are attributed to $\mathrm{Mo}_{8} \mathrm{O}_{26}{ }^{-4}$ species, ${ }^{52}$ which are easy to be reduced and presulfurized. The wide peaks in the region of $890-1000 \mathrm{~cm}^{-1}$ are assigned to $\mathrm{Mo}=\mathrm{O}$ bonds, which are considered as the active species for HDS reaction. ${ }^{53}$ According to Figure 10, the peak intensities of $\mathrm{Mo}=\mathrm{O}$ bonds increase following the sequence of NiMo/TD-3.0 $<$ NiMo/TD-0.25 $<$ NiMo/TD-0.5 $<$ NiMo/TD-1.0 < NiMo/TD-2.0. NiMo/TD-2.0 possesses more active sites that are easy to be reduced and presulfurized, which is in accordance with $\mathrm{H}_{2}-\mathrm{TPR}$ result.

\subsubsection{XPS}
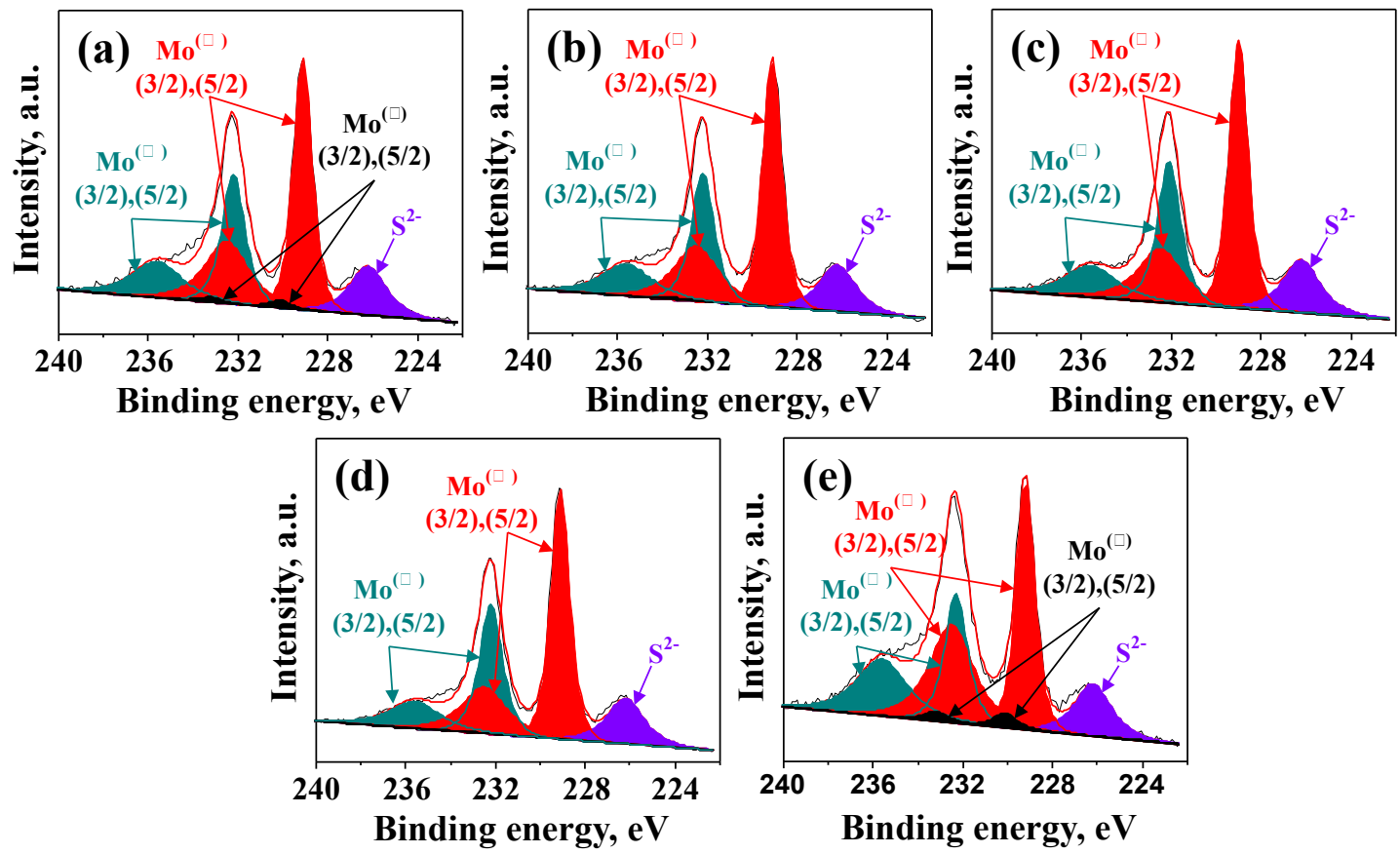

Figure 11. XPS spectra of various catalysts. (a) NiMo/TD-0.25;

(b) NiMo/TD-0.5; (c) NiMo/TD-1.0; (d) NiMo/TD-2.0 and (e) NiMo/TD-3.0

XPS spectra for obtaining the sulfurization degree for active metals of the spent NiMo/TD catalysts are presented in Figure 11. The peak-differentiating and imitating method for various sulfide Mo $3 \mathrm{~d} 5 / 2$ and Mo 3d3/2 species are referred to the reported work. ${ }^{54}$ The proportions of different Mo species over various catalysts are listed in Table 3. It presents that the proportion of $\mathrm{MoS}_{2}\left(\mathrm{Mo}^{4+}\right)$ increase following the sequence of NiMo/TD-3.0 (49 \%) < NiMo/TD-0.25 (60\%) < NiMo/TD-0.5 (62\%) < NiMo/TD-1.0 (66 \%) $<$ NiMo/TD-2.0 (68\%). This result manifests that 
NiMo/TD-2.0 possess higher proportion of active $\mathrm{MoS}_{2}$ phases than other NiMo/TD catalysts, which is in accordance with $\mathrm{H}_{2}$-TPR and Raman result.

Table 3. The proportions of different Mo species of various catalysts.

\begin{tabular}{|c|c|c|c|c|c|c|c|}
\hline \multirow{4}{*}{ Catalysts } & \multicolumn{2}{|c|}{$\mathrm{Mo}^{4+}$} & \multicolumn{2}{|c|}{$\mathrm{Mo}^{5+}$} & \multicolumn{2}{|c|}{$\mathrm{Mo}^{6+}$} & \multirow{4}{*}{$\mathrm{S}_{\mathrm{Mo}}{ }^{\mathrm{b}}$} \\
\hline & ar. $\%^{a}$ & & & & ar.\% & ar.\% & \\
\hline & $(229.1$ & $(232.2$ & $(230.1$ & $(233.2$ & $(232.5$ & $(235.6$ & \\
\hline & eV) & eV) & $\mathrm{eV})$ & eV) & eV) & eV) & \\
\hline NiMo/TD-0.25 & 36 & 24 & 2 & 1 & 22 & 15 & 60 \\
\hline NiMo/TD-0.5 & 37 & 25 & 2 & 1 & 21 & 14 & 62 \\
\hline NiMo/TD-1.0 & 40 & 26 & 1 & 1 & 19 & 13 & 66 \\
\hline NiMo/TD-2.0 & 41 & 27 & 1 & 1 & 18 & 12 & 68 \\
\hline NiMo/TD-3.0 & 29 & 20 & 3 & 2 & 27 & 19 & 49 \\
\hline
\end{tabular}

Note: ${ }^{\mathrm{a}}$ ar. $\%$ represents the area percentage of the peak.

${ }^{\mathrm{b}} \mathrm{S}_{\mathrm{Mo}}=\mathrm{Mo}_{\text {sulfidation }}=\mathrm{Mo}^{4+} /\left(\mathrm{Mo}^{4+}+\mathrm{Mo}^{5+}+\mathrm{Mo}^{6+}\right)$.

\subsubsection{HRTEM}

HRTEM photographs of series NiMo supported catalysts, as shown in Figure 12, present different stacking degree of $\mathrm{MoS}_{2}$ active phases. The stacking layer distributions and stacking length distribution of $\mathrm{MoS}_{2}$ for various NiMo supported catalysts are presented in Figure 12. The percentage of $\mathrm{MoS}_{2}$ species with higher stacking layers and higher stacking lengths display a declining trend with the increase of the CTAB/NaSal molar ratios. When the molar ratios of CTAB/NaSal are higher than 2.0, the percentage of $\mathrm{MoS}_{2}$ species with higher stacking layers and higher stacking lengths exhibit increasing tendencies. Moreover, the Nav, Lav and $f_{M o}$ for $\mathrm{MoS}_{2}$ phases are tabulated in Table 4. The $f_{M o}$ of active $\mathrm{MoS}_{2}$ of various sulfide catalysts increase following the sequence of NiMo/TD-3.0 $<\mathrm{NiMo} / \mathrm{TD}-0.25<$ NiMo/TD-0.5 < NiMo/TD-1.0 < NiMo/TD-2.0. Above all, NiMo/TD-2.0 catalyst shows the highest dispersion degree, the shortest stacking lengths, and the appropriate stacking layers, which are beneficial for improving the HDS activity. 

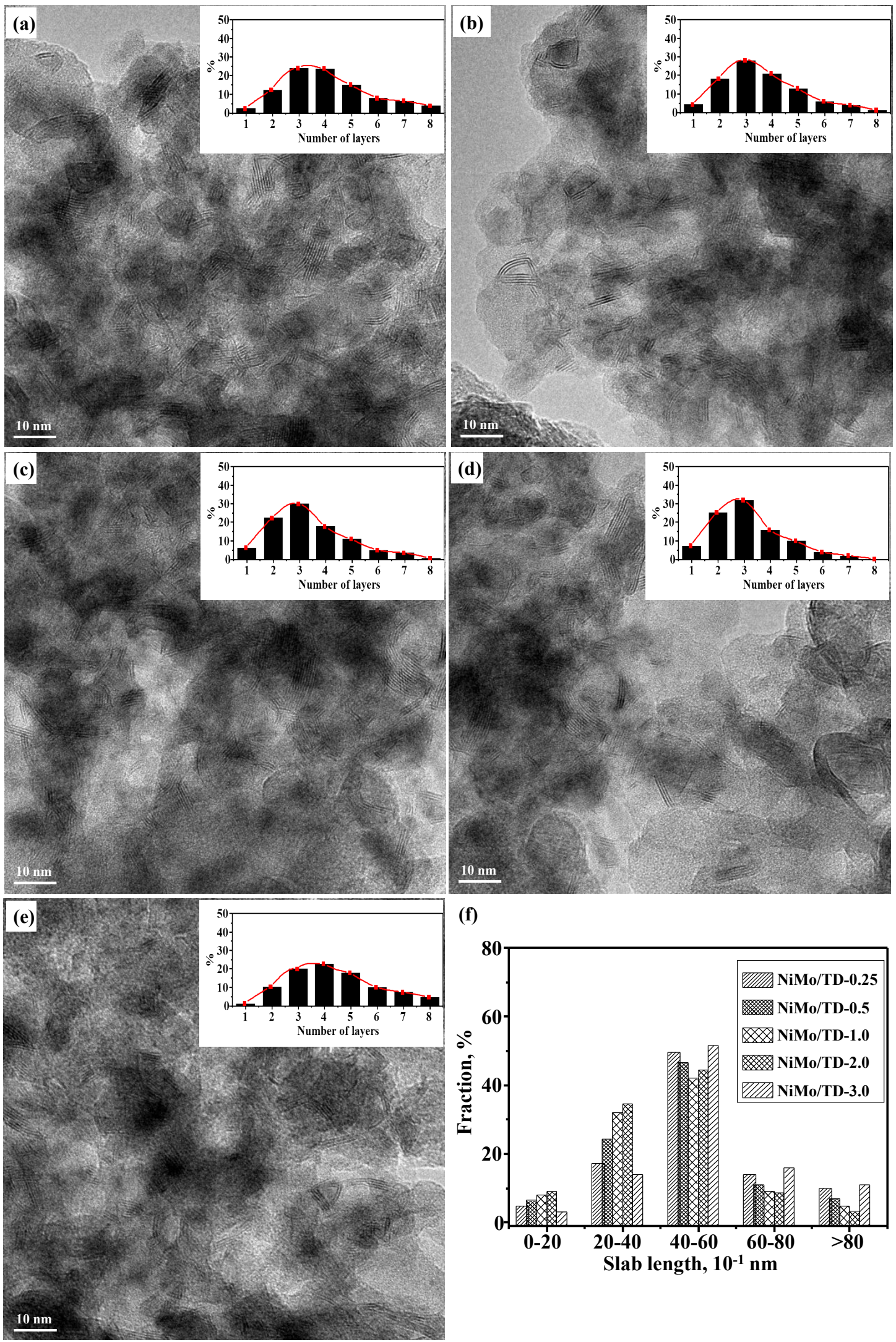

(f)

Figure 12. HRTEM photographs of various sulfide catalysts: (a) NiMo/TD-0.25;

(b) NiMo/TD-0.5; (c) NiMo/TD-1.0; (d) NiMo/TD-2.0; (e) NiMo/TD-3.0 and (f) stacking length distribution. 
Table 4. Lav and Nav of $\mathrm{MoS}_{2}$ species.

\begin{tabular}{cccc}
\hline Catalyst & Lav $(\mathrm{nm})$ & Nav & $f_{\text {Mo }}$ \\
\hline NiMo/TD-0.25 & 4.4 & 3.8 & 0.26 \\
NiMo/TD-0.5 & 3.9 & 3.3 & 0.32 \\
NiMo/TD-1.0 & 3.5 & 2.9 & 0.35 \\
NiMo/TD-2.0 & 3.3 & 2.8 & 0.37 \\
NiMo/TD-3.0 & 4.7 & 4.1 & 0.24 \\
\hline
\end{tabular}

\subsection{HDS of DBT}

The DBT HDS conversions of various NiMo supported catalysts are presented in Figure 13. During the WHSVs decrease from 100 to $10 \mathrm{~h}^{-1}$, the conversion rates of DBT over NiMo/TD catalysts increase following the sequence of NiMo/TD-3.0 < NiMo/TD-0.25 < NiMo/TD-0.5 < NiMo/TD-1.0 < NiMo/TD-2.0. And NiMo/TD-2.0 exhibits the highest DBT conversion among these NiMo/TD catalysts, the reference catalysts of NiMo/DMSNs, NiMo/TS-1 and NiMo/ $\mathrm{Al}_{2} \mathrm{O}_{3}$. When the CTAB/NaSal molar ratio continues to increase, the DBT conversion over NiMo/TD-3.0 decreases to some extent, which can be ascribed to its poor structural properties.

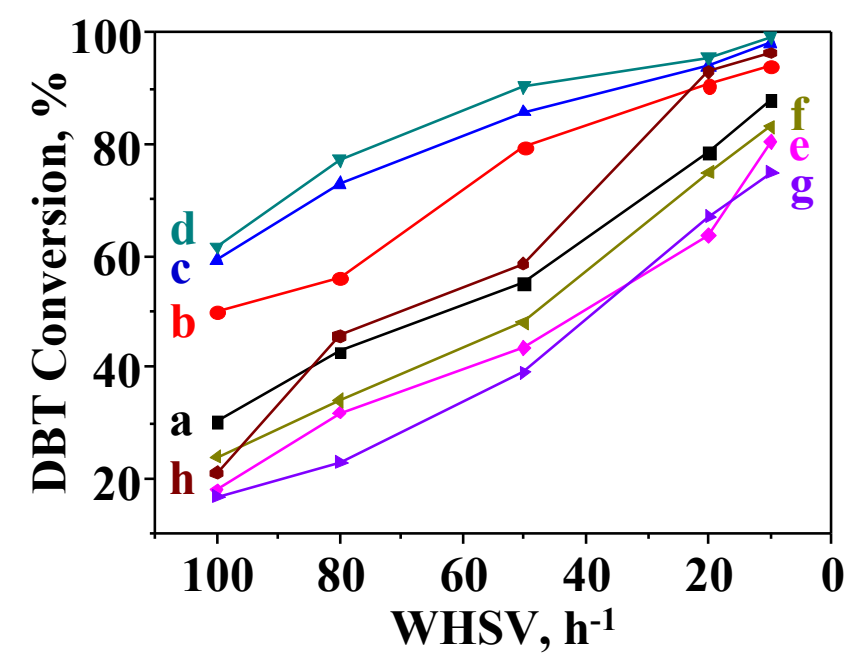

Figure 13. DBT HDS conversion over various NiMo catalysts: (a) NiMo/TD-0.25; (b) $\mathrm{NiMo} / \mathrm{TD}-0.5$; (c) NiMo/TD-1.0; (d) NiMo/TD-2.0; (e) NiMo/TD-3.0 (f) NiMo/DMSNs; (g) $\mathrm{NiMo} / \mathrm{TS}-1$ and (h) $\mathrm{NiMo} / \mathrm{Al}_{2} \mathrm{O}_{3}$.

For exploring the reaction pathway of DBT HDS, the products were analyzed using Gas Chromatography-Mass Spectrometer (GC-MS). The reaction mechanisms (Figures S2, Supporting Information) of DBT HDS can be proposed based on the 
product distributions. DBT undergoes direct desulfurization (DDS) pathway to remove the sulfur atom from the reactants directly. Another route proceeds HYD to remove the sulfur after the hydrogenation of the benzene ring. The DBT HDS product distributions of series NiMo catalysts are illustrated in Table 5. The HYD/DDS ratios of DBT over series sulfide catalysts increase following the sequence of NiMo/TD-3.0 $<\mathrm{NiMo} / \mathrm{TD}-0.25<\mathrm{NiMo} / \mathrm{TD}-0.5<\mathrm{NiMo} / \mathrm{TD}-1.0<\mathrm{NiMo} / \mathrm{TD}-2.0$. Moreover, the $k_{H D S}$ and TOF values of DBT on various sulfide catalysts also increase in the same sequence as above. NiMo/TD-2.0 presents the highest $k_{H D S}$, TOF values and HYD/DDS ratio compared with other catalysts. 
Table 5. DBT HDS results of various NiMo/TD catalysts.

\begin{tabular}{|c|c|c|c|c|c|c|c|c|c|c|c|}
\hline \multirow{3}{*}{ Catalyst } & \multirow{3}{*}{ Conversion $(\%)^{\mathrm{a}}$} & \multirow{3}{*}{$\begin{array}{l}k_{H D S} \\
\left(10^{-4} \mathrm{~mol}\right. \\
\left.\mathrm{g}^{-1} \mathrm{~h}^{-1}\right)\end{array}$} & \multirow{3}{*}{$\begin{array}{l}\mathrm{TOF}^{\mathrm{b}} \\
\left(\mathrm{h}^{-1}\right)\end{array}$} & \multicolumn{8}{|c|}{ Product selectivity (\%) } \\
\hline & & & & \multicolumn{6}{|c|}{ HYD } & \multirow{2}{*}{$\begin{array}{c}\text { DDS } \\
\mathrm{BP} \\
\end{array}$} & \multirow{2}{*}{$\begin{array}{l}\mathrm{HYD} / \mathrm{DDS} \\
\text { ratio }\end{array}$} \\
\hline & & & & THDBT & CHEB & PHDi & $\mathrm{CHB}$ & CPMB & $\mathrm{CPMCH}$ & & \\
\hline NiMo/TD-0.25 & 50.4 & 8.3 & 3.6 & 1 & 2 & 1 & 25 & 3 & 1 & 67 & 0.49 \\
\hline NiMo/TD-0.5 & 50.1 & 10.6 & 4.4 & 2 & 2 & 1 & 28 & 4 & 2 & 61 & 0.64 \\
\hline NiMo/TD-1.0 & 49.8 & 12.5 & 5.0 & 3 & 3 & 1 & 32 & 5 & 2 & 54 & 0.85 \\
\hline $\mathrm{NiMo} / \mathrm{TD}-2.0$ & 49.6 & 13.1 & 5.3 & 3 & 4 & 1 & 34 & 6 & 3 & 49 & 1.04 \\
\hline $\mathrm{NiMo} / \mathrm{TD}-3.0$ & 50.3 & 7.6 & 3.1 & 1 & 1 & 1 & 22 & 3 & 1 & 71 & 0.41 \\
\hline
\end{tabular}

${ }^{a}$ Acquired the total DBT HDS conversion of $50 \%$ through modulating WHSVs $\left(340{ }^{\circ} \mathrm{C}, 4.0 \mathrm{MPa}\right.$, and $\left.200 \mathrm{~mL} \mathrm{~mL}^{-1}\right)$.

${ }^{\mathrm{b}}$ Number of converted reactants per hour and per Mo atom.

HYD: Tetrahydrodibenzothiophene (THDBT) + Cyclohexenylbenzene (CHEB) + Isophenyl hexadiene $($ PHDi) + Cyclohexylbenzene $($ CHB) + Cyclopentylmethylbenzene (CPMB) + Cyclopentylmethylcyclohexane (CPMCH); DDS: Biphenyl (BP). 


\subsection{HDS of 4,6-DMDBT}

The 4,6-DMDBT HDS conversions of various catalysts are presented in Figure 14. During WHSVs decreasing from 100 to $10 \mathrm{~h}^{-1}$, the conversion rates of 4,6-DMDBT on various NiMo catalysts increase following the sequence of NiMo/TD-3.0 < NiMo/TD-0.25 < NiMo/TD-0.5 < NiMo/TD-1.0 < NiMo/TD-2.0. Especially, NiMo/TD-2.0 displays the highest 4,6-DMDBT HDS performance among these $\mathrm{NiMo} / \mathrm{TD}$ catalysts, the reference NiMo/DMSNs, NiMo/TS-1 and $\mathrm{NiMo} / \mathrm{Al}_{2} \mathrm{O}_{3}$ catalyst. The 4,6-DMDBT HDS conversion of NiMo/TD-3.0 decreases to some extent with the increase of the molar ratios of $\mathrm{CTAB} / \mathrm{NaSal}$.

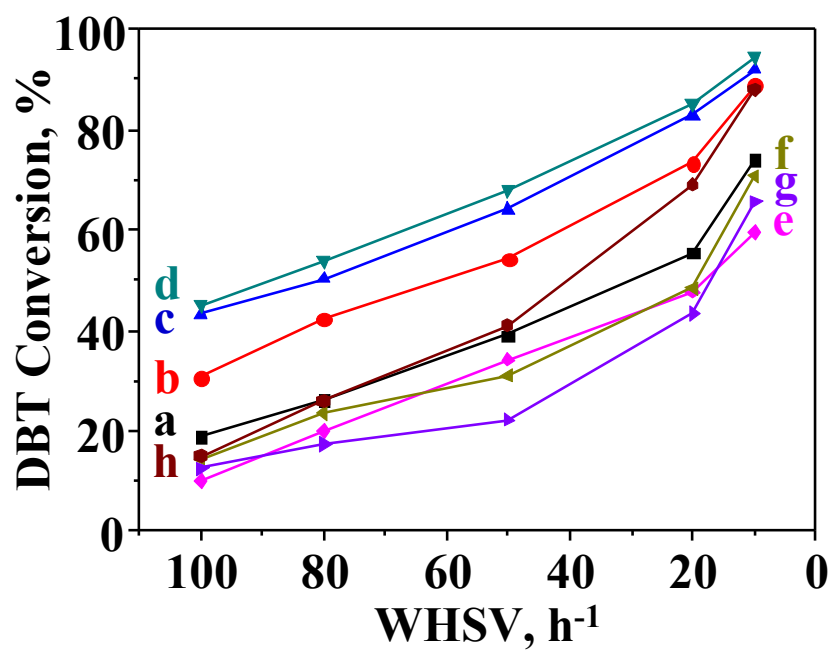

Figure 14. 4,6-DMDBT HDS conversion of various NiMo catalysts: (a) NiMo/TD-0.25; (b) NiMo/TD-0.5; (c) NiMo/TD-1.0; (d) NiMo/TD-2.0; (e) NiMo/TD-3.0; (f) NiMo/DMSNs; (g) $\mathrm{NiMo} / \mathrm{TS}-1$ and (h) $\mathrm{NiMo} / \mathrm{Al}_{2} \mathrm{O}_{3}$.

In order to explore the 4,6-DMDBT HDS reaction route of series NiMo catalysts, the products were analyzed by GC-MS. The reaction mechanisms (Figures S3, Supporting Information) of 4,6-DMDBT HDS can be proposed according to the product distribution. 4,6-DMDBT undergoes three reaction pathways to remove the sulfur from the reactants. Firstly, DDS pathway means the sulfur removed from reactants directly. Secondly, HYD removes sulfur after the hydrogenation of benzene ring. Thirdly, ISO pathway proceeds the sulfur removal along with HYD and DDS routes after the alkyl substitutes in 4,6-DMDBT $\mathrm{t}$ molecule are isomerized to further positions at first, i.e., to produce 3,7-DMDBT and 2,8-DMDBT. The product distribution of 4,6-DMDBT HDS on various NiMo catalysts is illustrated in Table 6. 
The 4,6-DMDBT ISO ratios of series NiMo catalysts increase following the sequence of NiMo/TD-3.0 < NiMo/TD-0.25 < NiMo/TD-0.5 < NiMo/TD-1.0 < NiMo/TD-2.0. Moreover, the $k_{H D S}$ and TOF of 4,6-DMDBT on various sulfide catalysts also increase

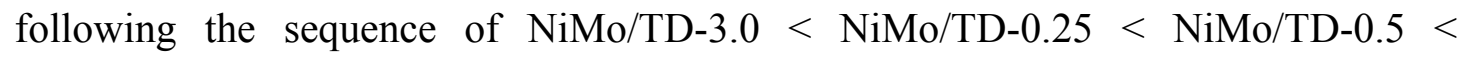
$\mathrm{NiMo} / \mathrm{TD}-1.0<\mathrm{NiMo} / \mathrm{TD}-2.0$. NiMo/TD-2.0 displays the highest $k_{H D S}$, TOF values and ISO ratio than other NiMo catalysts and reference $\mathrm{NiMo} / \mathrm{Al}_{2} \mathrm{O}_{3}$ catalysts. 
Table 6. 4,6-DMDBT HDS results of various NiMo/TD catalysts.

\begin{tabular}{|c|c|c|c|c|c|c|c|c|c|c|}
\hline \multirow{3}{*}{ Catalyst } & \multirow{3}{*}{$\begin{array}{l}\text { Conversion } \\
(\%)^{\mathrm{a}}\end{array}$} & \multirow{3}{*}{$\begin{array}{c}k_{H D S} \\
\left(10^{-4} \mathrm{~mol} \cdot\right. \\
\left.\mathrm{g}^{-1} \cdot \mathrm{h}^{-1}\right)\end{array}$} & \multirow{3}{*}{$\begin{array}{c}\mathrm{TOF}^{\mathrm{b}} \\
\left(\mathrm{h}^{-1}\right)\end{array}$} & \multicolumn{6}{|c|}{ Product selectivity (\%) } & \multirow{3}{*}{$\begin{array}{l}\text { Tota } \\
\text { ISO }\end{array}$} \\
\hline & & & & \multicolumn{3}{|c|}{ HYD } & \multirow{2}{*}{$\frac{\text { DDS }}{3,3^{\prime} \text {-DMBP }}$} & \multicolumn{2}{|c|}{ ISO } & \\
\hline & & & & $\begin{array}{l}\text { 4,6-THDMDBT+ } \\
\text { 4,6-HHDMDBT }\end{array}$ & 3,3'-DMCHB & 3,3'-DMBCH & & 4,4'-DMBP & $\begin{array}{l}\text { Iso- } \\
\text { MIPT }\end{array}$ & \\
\hline NiMo/TD-0.25 & 49.6 & 6.9 & 2.0 & 7 & 49 & 10 & 9 & 20 & 5 & 25 \\
\hline NiMo/TD-0.5 & 50.1 & 8.0 & 2.3 & 6 & 46 & 9 & 9 & 23 & 7 & 30 \\
\hline NiMo/TD-1.0 & 50.4 & 8.4 & 2.6 & 6 & 44 & 8 & 8 & 26 & 8 & 34 \\
\hline NiMo/TD-3.0 & 50.2 & 6.1 & 1.4 & 7 & 52 & 11 & 10 & 16 & 4 & 20 \\
\hline
\end{tabular}

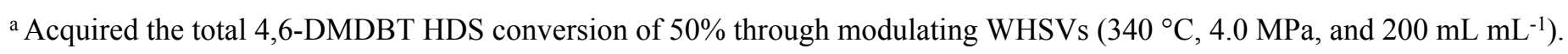

${ }^{b}$ Number of converted reactants per hour and per Mo atom.

HYD: 4,6-tetrahydrodimethyldibenzothiophene (4,6-THDMDBT) + 4,6-hexahydrodimethyldibenzothiophene (4,6-HHDMDBT) + 3,3'-dimethylcyclohexylbenzene (3,3'-DMCHB) + 3,3'-dimethylbicyclohexyl (3,3'-DMBCH); DDS: 3,3'-dimethylbiphenyl (3,3'-DMBP); Total ISO: 4,4'-dimethylbiphenyl (4,4'-DMBP) + Isomethylisopropyltetralin (Iso-MIPT) 


\section{DISCUSSION}

Dendritic TD composites with superior structural and acidic properties were successfully screened and designed. NiMo/TD-2.0 catalyst with ultrasmall particle size, uniform spherical dendritic morphology, suitable MSI, strong B\&L acidity and good stacking degree exhibit outstanding DBT and 4,6-DMDBT HDS activities. Combined with the systematical characterizations and activity assessments, the structure-function relationship is addressed as follows:

Firstly, the superior structural properties of dendritic TD supports contribute a lot to the diffusion of refractory DBT and 4,6-DMDBT reactants. The ultrasmall particle size $(\sim 90 \mathrm{~nm})$ of NiMo/TD-2.0 catalyst is not only beneficial to the uniform disperse of active metals due to its high surface areas $\left(575 \mathrm{~m}^{2} \cdot \mathrm{g}^{-1}\right)$, but also in favor of reducing the diffusion resistance and improving the accessibility of $\mathrm{MoS}_{2}$ to DBT and 4,6-DMDBT molecules due to its short diffusion paths between the reactants and the active metals.

Secondly, Ti elements of TS-1 seeds can release d-electrons by changing the valence states during the HDS reaction. The spillover d-electron moves to the surface of the $\mathrm{MoS}_{2}$ phases, thereby reducing Mo-S interactions and creating sulfur vacancies that are more favorable for DBT and 4,6-DMDBT HDS reaction.

Thirdly, the open dendritic pore structures (Figure 3) of the various TD materials can lower the diffusion resistance when the reactants and products diffuse through the pore channel, thus improving the DBT and 4,6-DMDBT performance of NiMo/TD catalysts (Figure 13 and 14). The uniform wrinkled surfaces (Figure 2) of the series TD supports can enhance the specific surface areas of the materials, facilitate the distribution of the metal species of the NiMo/TD catalyst surface and expose more active sites for DBT and 4,6-DMDBT HDS reactions. Moreover, the introduction of TS-1 seeds can boost the hydrothermal stability and mechanical strength of the NiMo/TD catalyst, thus extending the catalyst's shelf life.

Fourthly, TS-1 seeds and DMSNs were composited via Ti-O-Si chemical bond (Figures 4, 5, and 6), which positively affected the generation of B\&L acid (Figure 9). The increased B\&L acid amount of NiMo/TD-2.0 plays a crucial role in promoting 
the HYD route of DBT HDS (Table 5) and the ISO route of 4,6-DMDBT HDS (Table 6), which would be more favorable to the reduction of steric hindrance of DBT and 4,6-DMDBT reactants in the HDS reaction process.

Fifthly, NiMo/TD-2.0 catalyst possesses suitable MSI and more active species that are easy to be reduced and sulfurized (Figures 8 and 10), which is conducive to the production of $\mathrm{MoS}_{2}$ phases with the highest sulfurization degree (Figure 11), highest dispersion degree, the shortest stacking lengths and the appropriate stacking layers (Figure 12), thus increasing the $k_{H D S}$ and TOF of DBT and 4,6-DMDBT HDS (Tables 5 and 6).

\section{CONCLUSION}

Novel dendritic NiMo/TD-2.0 catalyst with ultrasmall particle size and more robust B\&L acidity are successfully prepared via a facile method. The ultrasmall particle size of NiMo/TD-2.0 catalyst can lower the diffusion resistance and improve the accessibility of $\mathrm{MoS}_{2}$ to DBT and 4,6-DMDBT reactant molecules. Moreover, the spillover d-electrons from TS-1 are beneficial to produce more sulfur vacancies of $\mathrm{MoS}_{2}$ species. The promotion of HYD route for DBT HDS and the ISO route for 4,6-DMDBT is favorable to the improvement of HDS activity on the NiMo/TD-2.0 catalyst. NiMo/TD-2.0 showed the highest $k_{H D S}$ and TOF values for DBT and 4,6-DMDBT than those of other $\mathrm{NiMo} / \mathrm{TD}$ and reference $\mathrm{NiMo} / \mathrm{Al}_{2} \mathrm{O}_{3}$ catalysts.

\section{Acknowledgment}

This work was financially supported by National Natural Science Foundation of China (No. 21878330 and 21808079), CNPC Key Research Project (2016E-0707), Key Research and Development Program of Shandong Province (No. 2019GSF109115), and the King Abdullah University of Science and Technology (KAUST) Office of Sponsored Research (OSR) under Award (No. OSR-2019-CPF-4103.2). 


\section{Supporting Information}

Characterization of the supports and catalysts; catalytic performance evaluation; chemicals needed in the experiments; TOF comparison of previous papers; preparation of TS-1/DMSNs composites with different particle size; HDS results of 4,6-DMDBT; possible reaction network of DBT HDS; possible reaction network of 4,6-DMDBT HDS; isomerization of 4,6-DMDBT to 3,7-DMDBT.

\section{REFERENCES}

[1] Yang, L.; Li, X.; Wang, A.; Prins, R.; Chen, Y.; Duan, X. Hydrodesulfurization of Dibenzothiophene, 4,6-Dimethyldibenzothiophene, and their Hydrogenated Intermediates over Bulk Tungsten Phosphide. J. Catal. 2015, 330, 330-343.

[2] Shan, S.; Yuan, P.; Han, W.; Shi, G.; Bao, X. Supported NiW Catalysts with Tunable Size and Morphology of Active Phases for Highly Selective Hydrodesulfurization of Fluid Catalytic Cracking Naphtha. J. Catal. 2015, 330, 288-301.

[3] Wang, X.; Mei, J.; Zhao, Z.; Zheng, P.; Chen, Z.; Li, J.; Fan, J.; Duan, A.; Xu, C. Restrictive Diffusion in the Hydrodesulfurization over Ni-MoS $2 / \mathrm{Al}_{2} \mathrm{O}_{3}$ with Different Crystal Forms. Ind. Eng. Chem. Res. 2017, 56, 10018-10027.

[4] Yik, E.; Iglesia, E. Mechanism and Site Requirements for Thiophene Hydrodesulfurization on Supported Re Domains in Metal or Sulfide Form. J. Catal. 2018, 368, 411-426.

[5] Zhou, W.; Wei, Q.; Zhou, Y.; Liu, M.; Ding, S.; Yang, Q. Hydrodesulfurization of 4,6-Dimethyldibenzothiophene over NiMo Sulfide Catalysts Supported on Meso-microporous Y Zeolite with Different Mesopore Sizes. Appl. Catal. B 2018, 238, 212-224.

[6] Wang, H.; Liu, S.; Smith, K. Understanding Selectivity Changes during Hydrodesulfurization of Dibenzothiophene on $\mathrm{Mo}_{2} \mathrm{C} /$ Carbon Catalysts. J. Catal. 2019, $369,427-439$.

[7] Zhou, W.; Zhou, A.; Zhang, Y.; Zhang, C.; Chen, Z.; Liu, L.; Zhou, Y.; Wei, Q.; 
Tao, X. Hydrodesulfurization of 4, 6-Dimethyldibenzothiophene over NiMo Supported on Ga-modified Y Zeolites Catalysts. J. Catal. 2019, 374, 345-359.

[8] Egorova, M.; Prins. R. Competitive Hydrodesulfurization of 4,6-Dimethyldibenzothiophene, Hydrodenitrogenation of 2-Methylpyridine, and Hydrogenation of Naphthalene over Sulfided NiMo/ $\gamma-\mathrm{Al}_{2} \mathrm{O}_{3}$. J. Catal. 2004, 224, 278-287.

[9] Zhang, D.; Duan, A.; Zhao, Z. Synthesis, Characterization, and Catalytic Performance of NiMo Catalysts Supported on Hierarchically Porous Beta-KIT-6 Material in the Hydrodesulfurization of Dibenzothiophene. J. Catal. 2010, 274, 273-286.

[10] Song, H.; Wang, J.; Wang, Z.; Song, H.; Li, F.; Jin, Z. Effect of Titanium Content on Dibenzothiophene HDS Performance over $\mathrm{Ni}_{2} \mathrm{P} / \mathrm{Ti}-\mathrm{MCM}-41$ Catalyst. $J$. Catal. 2014, 311, 257-265.

[11] Wang, X.; Zhao, Z.; Chen, Z.; Li, J.; Duan, A.; Xu, C.; Gao, D.; Cao, Z.; Zheng, P.; Fan, J. Effect of Synthesis Temperature on Structure-activity-relationship over $\mathrm{NiMo} / \gamma-\mathrm{Al}_{2} \mathrm{O}_{3}$ Catalysts for the Hydrodesulfurization of DBT and 4, 6-DMDBT. Fuel Process. Technol. 2017, 161, 52-61.

[12] Ho, T.; McConnachie, J.; Ultra-deep Hydrodesulfurization on $\mathrm{MoS}_{2}$ and $\mathrm{Co}_{0.1} \mathrm{MoS}_{2}$ : Intrinsic vs. Environmental Factors. J. Catal. 2011, 277, 117-122.

[13] Wang, X.; Du, P.; Chi, K.; Duan, A.; Xu, C.; Zhao, Z.; Chen, Z.; Zhang, H. Synthesis of NiMo Catalysts Supported on Mesoporous Silica FDU-12 with Different Morphologies and their Catalytic Performance of DBT HDS. Catal. Today 2017, 291, $146-152$

[14] Liang, J.; Wu, M.; Wei, P.; Zhao, J.; Huang, H.; Li, C.; Lu, Y.; Liu, Y.; Liu, C. Efficient Hydrodesulfurization Catalysts Derived from Strandberg PMoNi Polyoxometalates. J Catal. 2018, 358, 155-167.

[15] Zhang, L.; Fu, W.; Ke, Q.; Zhang, S.; Jin, H.; Hu, J.; Wang, S.; Tang, T.; Study of Hydrodesulfurization of 4, 6-DM-DBT over Pd Supported on Mesoporous USY Zeolite. Appl. Catal. A 2012, 433, 251-257.

[16] Zhang, L.; Fu, W.; Yu, Q.; Tang, T.; Zhao, Y.; Zhao, H.; Li, Y. Ni 2 P Clusters on 
Zeolite Nanosheet Assemblies with High Activity and good Stability in the Hydrodesulfurization of 4, 6-Dimethyldibenzothiophene. J. Catal. 2016, 338, 210-221.

[17] Zhang, L.; Fu, W.; Yu, Q.; Tang, T.; Zhao, Y.; Li, Y. Effect of Citric Acid Addition on the Morphology and Activity of $\mathrm{Ni}_{2} \mathrm{P}$ Supported on Mesoporous Zeolite ZSM-5 for the Hydrogenation of 4, 6-DMDBT and Phenanthrene. J. Catal. 2017, 345, 295-307.

[18) Fan, Y.; Xiao, H.; Shi, G.; Liu, H.; Qian, Y.; Wang, T.; Gong, G.; Bao, X. Citric Acid-assisted Hydrothermal Method for Preparing NiW/USY- $\mathrm{Al}_{2} \mathrm{O}_{3}$ Ultradeep Hydrodesulfurization Catalysts. J. Catal. 2011, 279, 27-35.

[19] Nikulshin, P.; Salnikov, V.; Mozhaev, A.; Minaev, P.; Kogan, V.; Pimerzin, A. Relationship between Active Phase Morphology and Catalytic Properties of the Carbon-Alumina-Supported Co(Ni)Mo Catalysts in HDS and HYD Reactions. $J$. Catal. 2014, 309, 386-396.

[20] van Haandel, L.; Bremmer, M.; Kooyman, P.; van Veen, J.; Weber, T.; Hensen, E. Structure-Activity Correlations in Hydrodesulfurization Reactions over Ni-Promoted $\mathrm{Mo}_{\mathrm{x}} \mathrm{W}_{(1-\mathrm{x})} \mathrm{S}_{2} / \mathrm{Al}_{2} \mathrm{O}_{3}$ Catalysts. ACS Catal. 2015, 5, 7276-7287.

[21] Shan, S.; Liu, H.; Yue, Y.; Shi, G.; Bao, X. Trimetallic WMoNi Diesel Ultra-deep Hydrodesulfurization Catalysts with Enhanced Synergism Prepared from Inorganic-Organic Hybrid Nanocrystals. J. Catal. 2016, 344, 325-333.

[22] Han, W.; Nie, H.; Long, X.; Li, M.; Yang, Q.; Li, D. Preparation of F-doped $\mathrm{MoS}_{2} / \mathrm{Al}_{2} \mathrm{O}_{3}$ Catalysts as a Way to Understand the Electronic Effects of the Support Brønsted Acidity on HDN Activity. J. Catal. 2016, 339, 135-142.

[23] Fu, W.; Zhang, L.; Tang, T.; Ke, Q.; Wang, S.; Hu, J.; Xiao, F. Extraordinarily High Activity in the Hydrodesulfurization of 4, 6-Dimethyldibenzothiophene over Pd Supported on Mesoporous Zeolite Y. J. Am. Chem. Soc. 2011, 133, 15346-15349.

[24] Tang, T.; Zhang, L.; Fu, W.; Ma, Y.; Xu, J.; Jiang, J.; Xiao, F. Design and Synthesis of Metal Sulfide Catalysts Supported on Zeolite Nanofiber Bundles with Unprecedented Hydrodesulfurization Activities. J. Am. Chem. Soc. 2013, 135, 11437-11440. 
[25] Wu, H.; Duan, A.; Zhao, Z.; Li, T.; Prins, R.; Zhou, X. Synthesis of NiMo Hydrodesulfurization Catalyst Supported on a Composite of Nano-sized ZSM-5 Zeolite Enwrapped with Mesoporous KIT-6 Material and its High Isomerization Selectivity. J. Catal. 2014, 317, 303-317.

[26] Bara, C.; Plais, L.; Larmier, K.; Devers, E.; Digne, M.; Lamic-Humblot, A.; Carrier, X. Aqueous-phase Preparation of Model HDS Catalysts on Planar Alumina Substrates: Support Effect on Mo Adsorption and Sulfidation. J. Am. Chem. Soc. 2015, $137,15915-15928$.

[27] Signorile, M.; Damin, A.; Budnyk, A.; Lamberti, C.; Puig-Molina, A.; Beato, P.; Bordiga, S. $\mathrm{MoS}_{2}$ Supported on P25 Titania: A Model System for the Activation of a HDS Catalyst. J. Catal. 2015, 328, 225-235.

[28] Vivero-Escoto, J.; Slowing, I.; Trewyn, B.; Lin, V. Mesoporous Silica Nanoparticles for Intracellular Controlled Drug Delivery. Small 2010, 6, 1952-1967.

[29] Wu, S.; Hung, Y.; Mou, C. Mesoporous Silica Nanoparticles as Nanocarriers. Chem. Commun. 2011, 47, 9972-9985.

[30] Shen, D.; Yang, J.; Li, X.; Zhou, L.; Zhang, R.; Li, W.; Chen, L.; Wang, R.; Zhang, F.; Zhao, D. Biphase Stratification Approach to Three-dimensional Dendritic Biodegradable Mesoporous Silica Nanospheres. Nano Lett. 2014, 14, 923-932.

[31] Yu, Y.; Xing, J.; Pang, J.; Jiang, S.; Lam, K.; Yang, T.; Xue, Q.; Zhang, K.; Wu, P. Facile Synthesis of Size Controllable Dendritic Mesoporous Silica Nanoparticles. ACS Appl. Mater. Inter. 2014, 6, 22655-22665.

[32] Huang, X.; Tao Jr., Z.; Praskavich, J.; Goswami, A.; Al-Sharab, J.; Minko, T.; Polshettiwar, V.; Asefa, T. Dendritic Silica Nanomaterials (KCC-1) with Fibrous Pore Structure Possess high DNA Adsorption Capacity and Effectively Deliver Genes in vitro. Langmuir 2014, 30, 10886-10898.

[33] Wang, X.; Xiao, C.; Zheng, P.; Zhao, Z.; Alabsi, M.; Shi, Y.; Gao, D.; Duan, A.; Huang, K.; Xu, C. Dendritic Micro-Mesoporous Composites with Center-Radial Pores Assembled by TS-1 Nanocrystals to Enhance Hydrodesulfurization Activity of Dibenzothiophene and 4, 6-Dimethyldibenzothiophene. J. Catal. 2020, 384, 136-146. [34]Wang, X.; Mei, J.; Zhao, Z.; Zheng, P.; Chen, Z.; Gao, D.; Fu, J.; Fan, J.; Duan, 
A.; Xu, C. Self-Assembly of Hierarchically Porous ZSM-5/SBA-16 with Different Morphologies and its High Isomerization Performance for Hydrodesulfurization of Dibenzothiophene and 4,6-Dimethyldibenzothiophene. ACS Catal. 2018, 8, 1891-1902.

[35] Sun, J.; Bonneau, C.; Cantin, Á.; Corma, A.; Diaz-Cabañas, M.; Moliner, M.; Zhang, D.; Li, M.; Zou, X. The ITQ-37 Mesoporous Chiral Zeolite. Nature 2009, 458, $1154-1157$.

[36] Moliner, M.; Martínez, C.; Corma, A. Multipore Zeolites: Synthesis and Catalytic Applications. Angew. Chem. Int. Ed. 2015, 54, 3560-3579.

[37] Nikolla, E.; Román-Leshkov, Y.; Moliner, M.; Davis, M. “One-pot” Synthesis of 5-(hydroxymethyl) Furfural from Carbohydrates using Tin-Beta Zeolite. ACS Catal. 2011, 1, 408-410.

[38] Ramírez, J.; Cedeño, L.; Busca, G. The Role of Titania Support in Mo-based Hydrodesulfurization Catalysts. J. Catal. 1999, 184, 59-67.

[39] Li, J.; Li, J.; Zhao, Z.; Fan, X.; Liu, J.; Wei, Y.; Duan, A.; Xie, Z. Liu, Q. Size Effect of TS-1 Supports on the Catalytic Performance of PtSn/TS-1 Catalysts for Propane Dehydrogenation. J. Catal. 2017, 352, 361-370.

[40] Wang, X.; Zhao, Z.; Zheng, P.; Chen, Z.; Duan, A.; Xu, C.; Jiao, J.; Zhang, H.; Cao, Z.; Ge, B. Synthesis of NiMo Catalysts Supported on Mesoporous $\mathrm{Al}_{2} \mathrm{O}_{3}$ with Different Crystal Forms and Superior Catalytic Performance for the Hydrodesulfurization of Dibenzothiophene and 4, 6-Dimethyldibenzothiophene. $J$. Catal. 2016, 344, 680-691.

[41] Duan, A.; Li, T.; Zhao, Z.; Liu, B.; Zhou, X.; Jiang, G.; Liu, J.; Wei, Y.; Pan, H. Synthesis of Hierarchically Porous L-KIT-6 Silica-Alumina Material and the Super Catalytic Performances for Hydrodesulfurization of Benzothiophene. Appl. Catal. B 2015, 165, 763-773.

[42] Gao, D.; Duan, A.; Zhang, X.; Zhao, Z.; E, H.; Li, J.; Wang, H. Synthesis of NiMo Catalysts Supported on Mesoporous Al-SBA-15 with Different Morphologies and their Catalytic Performance of DBT HDS. Appl. Catal. B 2015, 165, 269-284.

[43] Wang, X.; Li, Y.; Chi, K.; Zhao, Z.; Du, P.; Mei, J.; Zheng, P.; Fan, J.; Duan, A.; 
$\mathrm{Xu}$, C. Optimal Synthesis of Hierarchical Porous Composite ZSM-5/SBA-16 for Ultradeep Hydrodesulfurization of Dibenzothiophene and 4, 6-Dimethyldibenzothiophene. Part 1: The Influence of Inorganic Salt on the Properties of NiMo Catalysts. Energy fuels 2018, 32, 6204-6212.

[44] Wang, X.; Fan, J.; Zhao, Z.; Chen, Z.; Zheng, P.; Li, J.; Li, Y.; Han, L.; Duan, A. Xu, C. Hydro-upgrading Performance of Fluid Catalytic Cracking Diesel over Different Crystal Forms of Alumina-Supported CoMo Catalysts. Energy Fuels 2017, $31,7456-7463$.

[45] Lee, W.; Zhang, R.; Akatay, M.; Baertsch, C.; Stach, E.; Ribeiro, F.; Delgass, W. Differences in Catalytic Sites for CO Oxidation and Propylene Epoxidation on $\mathrm{Au}$ Nanoparticles. ACS Catal. 2011, 1, 1327-1330.

[46] Cao, Z.; Duan, A.; Zhao, Z.; Li, J.; Wei, Y.; Jiang, G.; Liu, J. A Simple Two-step Method to Synthesize the Well-ordered Mesoporous Composite Ti-FDU-12 and its Application in the Hydrodesulfurization of DBT and 4, 6-DMDBT. J. Mater. Chem. A 2014, 2, 19738-19749.

[47] Zhao, L.; Yu, J. Controlled Synthesis of Highly Dispersed $\mathrm{TiO}_{2}$ Nanoparticles using SBA-15 as Hard Template. J. Colloid Interface Sci. 2006, 304, 84-91.

[48] Hamdy, M.; Berg, O.; Jansen, J.; Maschmeyer, T.; Moulijn, J.; Mul, G. TiO 2 Nanoparticles in Mesoporous TUD-1: Synthesis, Characterization and Photocatalytic Performance in Propane Oxidation. Chem.-Eur. J. 2006, 12, 620-628.

[49] Wu, H.; Duan, A.; Zhao, Z.; Qi, D.; Li, J.; Liu, B.; Jiang, G.; Liu, J.; Wei, Y.; Zhang, X. Preparation of NiMo/KIT-6 Hydrodesulfurization Catalysts with Tunable Sulfidation and Dispersion Degrees of Active Phase by Addition of Citric Acid as Chelating Agent. Fuel 2014, 130, 203-210.

[50] Wang, X.; Du, P.; Zhao, Z.; Mei, J.; Chen, Z.; Li, Y.; Zheng, P.; Fan, J.; Duan, A. $\mathrm{Xu}$, C. Optimal Synthesis of Hierarchical Porous Composite ZSM-5/SBA-16 for Ultradeep Hydrodesulfurization of Dibenzothiophene and 4, 6-Dimethyldibenzothiophene. Part 2: The Influence of Aging Temperature on the Properties of NiMo Catalysts. Energy Fuels 2018, 32, 7800-7809.

[51] Biswas, P.; Narayanasarma, P.; Kotikalapudi, C.; Dalai, A.; Adjaye, J. 
Characterization and Activity of $\mathrm{ZrO}_{2}$ Doped SBA-15 Supported NiMo Catalysts for HDS and HDN of Bitumen Derived Heavy Gas Oil. Ind. Eng. Chem. Res. 2011, 50, 7882-7895.

[52] La Parola, V.; Deganello, G.; Tewell, C.; Venezia, A.; Structural Characterization of Silica Supported CoMo Catalysts by UV Raman Spectroscopy, XPS and X-ray Diffraction Techniques. Appl. Catal. A 2002, 235, 171-180.

[53] Zhou, X.; Duan, A.; Zhao, Z.; Gong, Y.; Wu, H.; Li, J.; Wei, Y.; Jiang, G.; Liu, J.; Zhang, Y. Synthesis of Hierarchically Porous Silicas with Mesophase Transformations in a Four-Component Microemulsion-type System and the Catalytic Performance for Dibenzothiophene Hydrodesulfurization. J. Mater. Chem. A 2014, 2, 6823-6833.

[54] Zhou, W.; Zhou, A.; Zhang, Y.; Zhang, C.; Chen, Z.; Liu, L.; Zhou, Y.; Wei, Q.; Tao, X. Hydrodesulfurization of 4, 6-Dimethyldibenzothiophene over NiMo Supported on Ga-modified Y Zeolites Catalysts. J. Catal. 2019, 374, 345-359. 


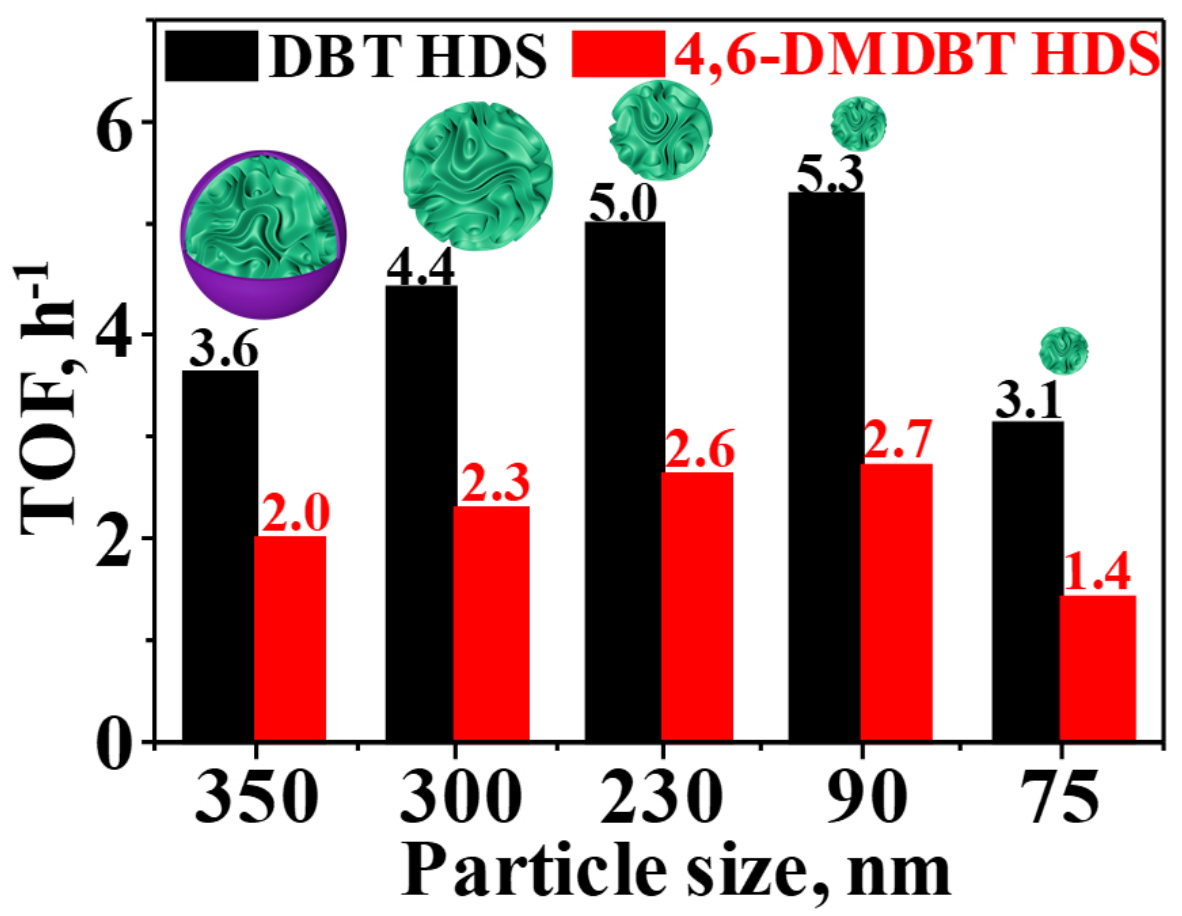

254x190mm (96 x 96 DPI) 